\title{
Investigation of the Influencing Soil Parameters on the Air Entry Values in Soil-Water Characteristic Curve of Compacted Heaving Soils
}

\author{
Armand Augustin Fondjo ${ }^{1, *}$, Elizabeth Theron ${ }^{1}$, Richard P. Ray ${ }^{2}$ \\ ${ }^{1}$ Department of Civil Engineering, Central University of Technology, South Africa \\ ${ }^{2}$ Structural and Geotechnical Engineering Department, Széchenyi István Egyetem University, Hungary
}

Received September 1, 2020; Revised October 14, 2020; Accepted November 11, 2020

\section{Cite This Paper in the following Citation Styles}

(a): [1] Armand Augustin Fondjo, Elizabeth Theron, Richard P. Ray, "Investigation of the Influencing Soil Parameters on the Air Entry Values in Soil-Water Characteristic Curve of Compacted Heaving Soils," Civil Engineering and Architecture, Vol. 9, No. 1, pp. 91-114, 2021. DOI: 10.13189/cea.2021.090108.

(b): Armand Augustin Fondjo, Elizabeth Theron, Richard P. Ray (2021). Investigation of the Influencing Soil Parameters on the Air Entry Values in Soil-Water Characteristic Curve of Compacted Heaving Soils. Civil Engineering and Architecture, 9(1), 91-114. DOI: 10.13189/cea.2021.090108.

Copyright $\mathrm{C} 2021$ by authors, all rights reserved. Authors agree that this article remains permanently open access under the terms of the Creative Commons Attribution License 4.0 International License

\begin{abstract}
The air-entry value (AEV) is a fundamental parameter of the soil-water characteristic curve (SWCC). $\mathrm{AEV}$ is the minimum matric suction value required for entry of air into soil voids. The primary objective of this research work is to assess the impact of geotechnical index properties, swelling properties, mineral composition on AEV of compacted heaving soils, and discuss how they affect AEV. Soil properties were investigated through lab tests such as grain size distribution (GSD), specific gravity, Atterberg limits, linear shrinkage, free swell index, free swell ratio, X-ray diffraction, compaction test, and soil suction measurement. SWRC Fit program was used to perform non-linear fitting of the SWCC based on models VG, DB, FX, LN, and BL. Surface plot of data was used to characterize the impact of soil properties on AEV. It was observed that AEV is ranging from $10 \mathrm{kPa}$ to 20.20 $\mathrm{kPa}$, models DB and BL gives the best fitting SWCC. The percent of smectite mineral exhibits a significant impact on AEV. Swelling properties such as free swell index and free swell ratio influence the AEV with a respective determination coefficient of $85.72 \%, 88.68 \%$. The plasticity index, linear shrinkage, specific gravity, and dry unit weight impact the AEV with a respective determination coefficient of $95 \%, 95.45 \%, 90.43 \%$, $94.29 \%$. The fine-grained content, clay fraction, void ratio, and water content influence the AEV with a respective determination coefficient of $97.95 \%, 84.89 \%, 80 \%$,
\end{abstract}

94.31\%. The finer the soil, the higher the AEV. The activity of clay and percent of illite mineral exhibit a marginal effect on the AEV.

Keywords Air-entry Value, Soil-water Characteristic Curve, Heaving Soils, Soil Parameters

\section{Introduction and Background}

Reference [1] defined the air-entry value (AEV) as the matric suction value where the air begins to enter the largest pores in the soil. The AEV is also called the bubbling pressure. AEV is a significant parameter of the SWCC. The SWCC describes the thermodynamic potential of the pore water in the soil relative to free water as a function of water fraction consumed by the soil material [2]. The SWCC plays a key role in non-saturated soil mechanics, which is a new field of study with wide applications in geotechnical engineering. Unsaturated soil properties such as AEV, GSD, volume strain, shear stress, water content in the pores at any suction can be determined using the SWCC. The maximum pore size distribution through all the soil body is commonly significant in AEV estimation. The primary objective of this research work is to assess the impact of geotechnical index properties, swelling 
properties, mineral composition on the AEV of compacted heaving soils and discussed how they affect the AEV. Some precedent investigations have been reported in the literature. The review of the soil parameters that influence the AEV cannot be dissociated from the soil properties that affect the SWCC because the AEV is a feature of the SWCC. Therefore, the parameters affecting the AEV and the SWCC are mentioned in the literature review.

Reference [3] reported that the plasticity index (PI) influences the SWCC. PI is an estimation of the capacity of the water-holding of soil and impacts the shape of the SWCC. Reference [4] assessed the factors that impact SWCC utilizing a 15 bar pressure plate. It was discovered that the SWCC is influenced by the PI. Another investigation conducted by [5] shows that the PI can be utilized to predict the SWCC and the AEV. Nonetheless, these studies do not specify the type and the nature of the correlation between PI and the AEV. Reference [6] reported the impact of shrinkage on the AEV of heaving soils. The analysis reveals that the AEV relies upon the SWCC when the soil suction increases and the void ratio of the shrinkage graph displays a significant impact on SWCC. Besides, this study does not mention the nature and the type of relationship between shrinkage and the AEV. Reference [7] studied the SWCC of compacted heaving soils at the various dry unit weights. The results revealed that the shape of the SWCC relies upon the dry unit weight of the specimen. The AEV of SWCC increases when the dry unit weight increases. The study does not mention the type of correlation between the AEV and the dry unit weight. Reference [4] reported that the dry unit weight influences the SWCC. Reference [10] examined the impact of dry unit weight on the SWCC. The GSD of the sample was analyzed utilizing a mercury porosimetry test to assess the impact of the dry unit weight. It was discovered that the SWCC of soil samples was significantly dependent on the dry unit weight. However, [9] analyzed the impacts of initial dry unit weight on the SWCC of loose soil utilizing a pressure plate. The residual water content increases with the augmentation of initial dry unit weight, and the initial dry unit weight has marginal effects on AEV. Another investigation conducted by [10] in the laboratory on the drying and wetting SWCC for sandy soil with different dry unit weight revealed that the SWCC is strongly dependent on the dry unit weight of the soil sample. These studies confirm the influence of the dry unit weight on the SWCC. Even though the AEV is related to the SWCC and the dry unit weight has marginal effects on $\mathrm{AEV}$, investigate the influence of the dry unit weight on the AEV of compacted heaving soil is necessary.

Reference [3] predicted the SWCC using the GSD. Their findings reported that the GSD of soil is related to the pore size distribution and holds a strong relationship with the SWCC. Reference [4] investigated the influence of GSD on SWCC and reported that the SWCC depends on GSD. Reference [11] reported that the behaviour of non-saturated soil depends considerably on the GSD. Reference [5] attempted to the prediction of the SWCC. The results revealed that the GSD is a good predictor of the SWCC and the AEV. These studies show that the GSD and the SWCC are strongly related. The GSD defines the distribution of the grains, and SWCC characterized the distribution of the voids in the soil. Besides, the investigation of the impacts of the GSD parameters such as coefficient of curvature, coefficient of uniformity, clay content, and fine-grained content on the AEV is essential. Reference [12] investigated the impact of the initial amount of water and void ratio on SWCC. It was observed that the initial amount of water impacts the SWCC than the void ratio. Reference [13] reported the impact of the initial void ratio on the SWCC, specimens were set up in a modified oedometer apparatus for non-saturated soils. The suction was applied using a pressure plate. The AEV is found inversely proportional to the void ratio. Another research by [14] stated that the void ratio is one of the key parameters that impact the SWCC. However, the initial amount of water exhibits the best influence on the soil structure that controls the SWCC. These studies do not specify the type of correlation between the void ratio and the AEV or SWCC.

Reference [12] studied the impact of the initial amount of water on SWCC. It was observed that the initial amount of water impacts the SWCC than the void ratio. Reference [15] reviewed the factors impacting the SWCC. It was discovered that the initial amount of water affects the SWCC than the dry unit weight. Also, the impact of soil properties on the SWCC depends on the type of soil. Besides, further studies are required to measure the effect of other soil parameters on the SWCC. Reference [14] reported that the initial amount of water regularly has the best impact on the SWCC. Reference [9] performed a laboratory test to analyze the impact of water content on the SWCC of compacted soil specimens. It was observed that compacted soil specimen upon a higher initial amount of water exhibits residual water content and a higher AEV. Reference [16] studied the relationship between the features of SWCC and the percent of smectite mineral (PSM) in soil. The SWCC data is determined using three fitting models: Brooks \& Corey, Van Genuchten, Fredlund $\&$ Xing. The findings revealed that the PSM influences the SWCC parameters like the AEV. References $[14,4]$ reported that the soil mineralogy influences the SWCC. Another study by [11] reported the influence of clay mineral on non-saturated soil. The finding reveals that the behaviour of non-saturated soil depends considerably on the GSD and clay mineral. However, some studies do not specify the type of clay mineral and the level of impact on the AEV. Therefore, the influence of other clay minerals is needed.

In engineering practice, the soil shear resistance is used to examine the slope stability, bearing limit of foundation, lateral pressure on earth-retaining structures. In 
non-saturated soils, the SWCC and AEV can be used for the prediction of common soil properties and the shear resistance.

The review of the literature reported that few research works were conducted on the correlation between soil properties and AEV of compacted heaving soils to assess the impact of soil properties on AEV. The correlation characteristics are not mentioned in some cases. Besides, the impact on AEV of soil properties such as specific gravity, free swell ratio, free swell index, and activity of clay is not reported in the literature. Moreover, researchers have focused their investigations mainly on soil properties that influence the SWCC in developing predictive models for SWCC using soil properties. AEV is an essential parameter related to SWCC. Nevertheless, an investigation of the impact of geotechnical properties, swelling properties, and soil mineralogy on AEV of compacted heaving soils is essential.

\section{Testing Program}

\subsection{Sampling Locations}

Soil samples are obtained by digging out from the site across South Africa. Bloemfontein soils (BFS-A; BFS-B; BFS-C); Winburg soils (WIS-A; WIS-B; WIS-C); Welkom soils (WES-A; WES-B; WES-C). The GPS coordinates are (BFS-A: $29^{\circ} 11^{\prime} 49.53 " \mathrm{~S} ; 26^{\circ} 12^{\prime} 52.55 \mathrm{E}$ ); (BFS-B: $\quad 29^{\circ} 08^{\prime} 04.40^{\prime \prime S}$; $\left.26^{\circ} 15^{\prime} 58.10^{\prime \prime} \mathrm{E}\right)$; (BFS-C: $29^{\circ} 06^{\prime} 48.20^{\prime \prime} \mathrm{S} ; 26^{\circ} 10^{\prime} 56.70 " \mathrm{E}$ ). (WIS-A: $28^{\circ} 30^{\prime} 43.5^{\prime \prime} \mathrm{S}$; $27^{\circ} 00^{\prime} 12.8^{\prime \prime} \mathrm{E}$ ); (WIS-B: $28^{\circ} 30^{\prime} 59.8^{\prime \prime} \mathrm{S} ; 27^{\circ} 00^{\prime} 58.0^{\prime \prime} \mathrm{E}$ ); (WIS-C: $\quad 28^{\circ} 31^{\prime} 08.00^{\prime \prime S} ; \quad 27^{\circ} 00^{\prime} 22.00^{\prime \prime E}$ ). (WES-A: $27^{\circ} 57^{\prime} 51.8^{\prime \prime S}$; $26^{\circ} 45^{\prime} 36.9^{\prime \prime E}$ ); (WES-B: $28^{\circ} 00^{\prime} 12.10^{\prime \prime}$; $26^{\circ} 43^{\prime} \quad 52.30^{\prime \prime} \mathrm{E}$ ); (WES-C: $27^{\circ} 58^{\prime} 15.10^{\prime \prime} \mathrm{S}$; $\left.26^{\circ} 43^{\prime} 05.00^{\prime \prime} \mathrm{E}\right)$.

\subsection{Laboratory Investigations}

To assess the physical and hydro-mechanical properties of the soils, laid down protocols and standards found in the literature were utilized: Linear shrinkage [17]; sieve analysis [18]; hydrometer analysis [19]; specific gravity [20]; Atterberg limits [21]; free swell index [22]; free swell ratio [23]; X-ray diffraction technique [24]; Proctor compaction test [25]; Soil suction measurement using filter paper technique [26]; Soil-water characteristic curve models: $[27,28,1,29,30]$.

\subsubsection{Linear Shrinkage}

The linear shrinkage of soil specimen is the decrease in length calculated as a proportion of the initial length of the soil mass when the amount of water is reduced from the liquid limit to an oven-dried state. After the one-point liquid limit test (LL), the excess wet material was used to fill the trough with no extra mixing. The number of blows to close the channel was recorded for the last liquid limit measurement. The trough was filled up with material, put in the oven, and dried overnight at a temperature of $105^{\circ} \mathrm{C}$ until the shrinkage stopped. The number of blows of the LL test, designated by $(\mathrm{N})$; the linear shrinkage, denoted by (Ls) is reported to the nearest $0.5 \%$ and determined from Equation (1).

$$
\begin{gathered}
\mathrm{L}_{\mathrm{S}}(\%)=\text { Shrinkage in } \mathrm{mm} \text { as measured } \times\left[\frac{100}{150} \times\right. \\
\left.\frac{0.8}{1-0.008 \times \mathrm{N}}\right]
\end{gathered}
$$

\subsubsection{Void Ratio}

The void ratio denoted by (e) is assessed utilizing the soil parameters as follows: the specific gravity $\left(G_{s}\right)$, the dry weight of water $\left(\gamma_{w}\right)$, and the dry unit weight of the soil $\left(\gamma_{d}\right)$, and calculate from the following formula:

$$
\mathrm{e}=\mathrm{G}_{\mathrm{S}} \times \frac{\gamma_{\mathrm{w}}}{\gamma_{\mathrm{d}}}-1
$$

\subsubsection{Soil Suction Estimation}

Equation (3) of the calibration curve was obtained through a calibration process of Whatman No 42 filter paper making use of a solution of salt. The moisture content inside the filter paper, designated by $\left(\mathrm{W}_{\mathrm{f}}\right)$, was evaluated utilizing Equation (4). After, the determined moisture content value was put in Equation (3) to compute soil suction. Compacted cylindrical soil specimens were split into two parts with a width of $75 \mathrm{~mm}$ and a deepness of $35 \mathrm{~mm}$ so that the soil specimen can be placed and withdraw from the glass container without any problem. The suction evaluation was performed utilizing the Whatman No 42 filter paper (Ashless circles $70 \mathrm{~mm}$ diameter Cat No 1442-070). Three filter papers (two protectives and one for suction evaluation with $70 \mathrm{~mm}$ diameter) were set between these two surfaces utilizing tweezers for matric suction estimation. The two divided parts of the specimen were joined utilizing electrical tape and insert into a glass container. A plastic ring was put on top of the specimen. The filter papers are set on top of the plastic ring to gauge the total suction. The glass containers were sealed, named, and put into a temperature regulatory equipment at $25 \pm 1^{\circ} \mathrm{C}$ for a period of equilibrium of about a month. Filter papers were oven-dried to expel moisture and guarantee that a similar wetting way is followed for each situation to prevent hysteresis effect. Moisture cans were oven-dried at $105^{\circ} \mathrm{C}$ overnight. Filter paper moisture content was estimated utilizing a $0.0001 \mathrm{~g}$ readable balance. The filter paper water content denoted by $\left(\mathrm{W}_{\mathrm{f}}\right)$; the mass of water in the filter paper, represented by $\left(\mathrm{M}_{\mathrm{w}}\right)$; and the mass of the filter paper, designated by $\left(\mathrm{M}_{\mathrm{f}}\right)$. The soil suction, denoted by $(\psi)$ in $\mathrm{kPa}$ is given as:

$$
\begin{gathered}
\log (\psi)=-0.0791 \times \mathrm{W}_{\mathrm{f}}+5.313 \\
\mathrm{~W}_{\mathrm{f}}=\frac{\mathrm{M}_{\mathrm{w}}}{\mathrm{M}_{\mathrm{f}}} \times 100
\end{gathered}
$$

\subsection{Modeling of Soil-water Characteristic Curves}

Many empirical, analytical, and statistical models were 
developed to fit the experimental data and describe the SWCC. The measured volumetric water content values obtained from the experiments were compared to the predicted volumetric water content values, based on the matric suction values obtained from the models proposed by VG [27], DB [28], FX [1], LN [29] and BL [30]. SWCC modal types are summarized in Table 1 . In this research work, the SWRC Fit program was used to perform the non-linear fitting of SWCCs using the five models above mentioned, estimate the fitting parameters, determination coefficient, and Akaike information criterion (AIC). SWRC Fit program utilizes a computation language GNU Octave [30]. A logarithmic scale was used because of the higher range of soil suction values. The AEV was determined to fit the best-SWCC model. Soil suction values were determined accurately at different moisture content on compacted specimens using Whatman No 42 filter paper, other soil suction values by interpolating the measured values.

Reference [27] developed a mathematical equation model (VG) as a fitting equation for the SWCC that is written in $\theta(\psi)$ functional form.

$$
\theta(\psi)=\theta_{\mathrm{r}}+\frac{\left(\theta_{\mathrm{S}}-\theta_{\mathrm{r}}\right)}{\left[1+(\alpha \psi)^{\mathrm{n}}\right]^{1-1 / n}}
$$

The SWCC model (DB) proposed by [28] is given in Equation 6. The volumetric water content at any suction is written in $\theta(\psi)$ functional form.

$$
\theta(\psi)=\theta_{\mathrm{r}}+\mathrm{w}_{1}\left[\frac{\left(\theta_{\mathrm{s}}-\theta_{\mathrm{r}}\right)}{1+\left(\alpha_{1} \psi\right)^{\mathrm{n}_{1}}}\right]^{\mathrm{m}_{1}}+\left(1-\mathrm{w}_{1}\right)\left[\frac{\left(\theta_{\mathrm{s}}-\theta_{\mathrm{r}}\right)}{1+\left(\alpha_{2} \psi\right)^{\mathrm{n}_{2}}}\right]^{\mathrm{m}_{2}}
$$

Reference [1] developed a mathematical equation model (FX) as a fitting equation for SWCC that is written in $\theta(\psi)$ functional form.

$$
\theta(\psi)=C(\psi) \frac{\theta_{s}}{\left[\ln \left[e+\left(\frac{\psi}{a}\right)^{n}\right]\right]^{m}}=\left[\frac{\ln \left(1+\frac{\psi}{C_{r}}\right)}{\ln \left[1+\left(1+\frac{10^{6}}{C_{r}}\right)\right]}\right] \frac{\theta_{s}}{\left\{\ln \left[e+\left(\frac{\psi}{a}\right)^{n}\right]\right\}^{m}}
$$

The SWCC model (LN) proposed by [29] is given in
Equation 8. The volumetric water content at any suction is written in $\theta(\psi)$ functional form.

$$
\theta(\psi)=\theta_{\mathrm{r}}+\mathrm{Q}\left[\frac{\left(\theta_{\mathrm{s}}-\theta_{\mathrm{r}}\right) \ln \left(\frac{\psi}{\psi_{\mathrm{m}}}\right)}{\sigma}\right]
$$

Reference [30] developed a mathematical equation model (BL) as a fitting equation for SWCC that is written in $\theta(\psi)$ functional form.

$$
\begin{gathered}
\theta(\psi)=\theta_{\mathrm{r}}+\left(\theta_{\mathrm{s}}-\theta_{\mathrm{r}}\right) \mathrm{w}_{1} \mathrm{Q}\left[\left(\frac{\ln \left(\frac{\psi}{\psi_{\mathrm{m} 1}}\right)}{\sigma_{1}}\right)+(1-\right. \\
\left.\left.\mathrm{w}_{1}\right) \mathrm{Q}\left(\frac{\ln \left(\frac{\psi}{\psi_{\mathrm{m} 2}}\right)}{\sigma_{2}}\right)\right]
\end{gathered}
$$

Table 1. Soil-water characteristic curves modal types

\begin{tabular}{|c|c|c|}
\hline References & Unimodal & Bimodal \\
\hline$[27]$ & VG & - \\
\hline$[28]$ & - & DB \\
\hline$[1]$ & FX & - \\
\hline$[29]$ & LN & - \\
\hline$[30]$ & - & BL \\
\hline
\end{tabular}

\section{Results and Discussions}

\subsection{Materials Properties}

The material properties of soil samples used in this research work are summarized in Table 2. BFS, WIS, WES are fine-grained soil, more than $50 \%$ passed through sieve No $200(0,075 \mathrm{~mm})$. The linear shrinkage values of these soils are $>5 \%$. The activity of the clay values $\left(A_{c}>1\right)$, the soils are not well graded because of the coefficient of

\begin{tabular}{|c|c|c|c|c|c|c|c|c|c|c|}
\hline \multicolumn{2}{|c|}{$\begin{array}{c}\text { Soil } \\
\text { Designation }\end{array}$} & $\begin{array}{c}\text { Plasticity } \\
\text { index }\end{array}$ & $\begin{array}{c}\text { Linear } \\
\text { shrinkage }\end{array}$ & $\begin{array}{l}\text { clay } \\
(\%)\end{array}$ & $\begin{array}{r}\text { Fine } \\
(\%)\end{array}$ & $\begin{array}{c}\text { Sand } \\
(\%)\end{array}$ & $\begin{array}{c}\text { Gravel } \\
(\%)\end{array}$ & $\begin{array}{l}\text { Activity of } \\
\text { clay } \\
\text { (A) }\end{array}$ & $\begin{array}{c}\text { Coef } \\
\text { of } \\
\text { curvature }\end{array}$ & USCS \\
\hline \multirow{3}{*}{ BFS } & BFS-A & 36.82 & 9.283 & 30.4 & 59.51 & 29.39 & 10.09 & 1.21 & 160 & $\mathrm{CH}$ \\
\hline & BFS-B & 38.25 & 8.933 & 32.2 & 61.82 & 29.49 & 8.38 & 1.19 & 150 & $\mathrm{CH}$ \\
\hline & BFS-C & 40.33 & 8.474 & 35.07 & 65.18 & 30.48 & 4.32 & 1.15 & 125 & $\mathrm{CH}$ \\
\hline \multirow{3}{*}{ WIS } & WIS-A & 42.48 & 7.693 & 34.03 & 67.52 & 26.8 & 4.85 & 1.25 & 105.88 & $\mathrm{CH}$ \\
\hline & WIS-B & 44.10 & 7.413 & 36.5 & 70.1 & 27.2 & 2.45 & 1.21 & 166.67 & $\mathrm{CH}$ \\
\hline & WIS-C & 47.04 & 6.973 & 39.73 & 74.78 & 23.98 & 1.21 & 1.18 & 113.04 & $\mathrm{CH}$ \\
\hline \multirow{3}{*}{ WES } & WES-A & 49.87 & 6.123 & 40 & 73 & 23.5 & 2.56 & 1.25 & 90.90 & $\mathrm{CH}$ \\
\hline & WES-B & 53.36 & 5.723 & 48.31 & 78.11 & 18.71 & 1.98 & 1,13 & 43.33 & $\mathrm{CH}$ \\
\hline & WES-C & 56.68 & 5.383 & 55.25 & 82.98 & 15.92 & 1.10 & 1.03 & 13.33 & $\mathrm{CH}$ \\
\hline
\end{tabular}
curvature $\left(\mathrm{C}_{\mathrm{c}}>1\right)$. The liquid limit values of these soils are $>$ $50 \%$, above the ' $\mathrm{A}$ ' line of the plasticity chart. These soils exhibit high plasticity, shrinkage properties when drying, swelling features upon wetting and are classified as $(\mathrm{CH})$.

Table 2. Material properties 


\subsection{Hydro-mechanical Properties Analysis}

Compaction is the solidification of soil and the rearrangement of soil particles by driving out air void using mechanical equipment. This technique is used to improve soil strength in construction. The dry unit weight of the soil is a reference parameter to determine the degree of compaction. The results are summarized in Table 3 . The maximum dry unit weight (MDUW) values are of the order of $15 \mathrm{kN} / \mathrm{m}^{3}$ to $18 \mathrm{kN} / \mathrm{m}^{3}$. The OWC values are within the range of $20 \%$ to $28 \%$, which is the range of low and high plasticity clay. WES displays smaller values of MDUW and higher values of OWC. WIS exhibits the mean values of OWC and MDUW. BFS displays the higher values of MDUW and smaller values of OWC. The matric suction values are of the order of $671.89 \mathrm{kPa}$ to $2021.82 \mathrm{kPa}$ at OWC. Some of the matric suction values are greater than the maximum matric suction range of the pressure plate, imperial college tensiometer, electrical conductivity sensor, thermal conductivity sensor, and time domain reflectometry limited at $1500 \mathrm{kPa}$. Therefore, the in-contact filter paper technique is selected. WES exhibits the higher matric suction values, BFS the smaller matric suction values, and WIS the mean matric suction values. This can be clarified by the contrasts between the fine-grained soils. When the fine-grained content increases, the dry unit weight decreases, the OWC increases, and the matric suction increases. The void ratio values derived from Equation (2) are of other of 0.692 to 0.937 . The specific gravity values of soils across the area of investigation are found to be relatively high, of the order of 2.65 to 2.83 .

\subsection{X-ray Diffraction Analysis}

The results revealed that smectite is the most important clay mineral in these soils. A limited quantity of illite and trace of illite were found. Moreover, silica and the group of feldspar minerals (plagioclase, k-feldspar) are the predominant non-clay mineral. A little amount of calcite and trace of calcite were found. The significant content in smectite can explain the swelling features of these soils.

Table 3. Hydro-mechanical properties

\begin{tabular}{|c|c|c|c|c|c|c|}
\hline Soil designation & Samples & $\begin{array}{c}\text { Optimum } \\
\text { water content } \\
\% \\
\end{array}$ & $\begin{array}{c}\text { Maximum dry } \\
\text { unit weight } \\
\mathrm{kN} / \mathrm{m}^{3}\end{array}$ & $\begin{array}{c}\text { Specific gravity } \\
\text { (Gs) }\end{array}$ & Void ratio (e) & $\begin{array}{c}\text { Matric suction } \\
\mathrm{kPa}\end{array}$ \\
\hline \multirow{3}{*}{ BFS } & BFS-A & 20.07 & 17.58 & 2.65 & 0.692 & 671.89 \\
\hline & BFS-B & 22.61 & 17.16 & 2.68 & 0.769 & 697.98 \\
\hline & BFS-C & 23.00 & 16.95 & 2.71 & 0.810 & 735.90 \\
\hline \multirow{3}{*}{ WIS } & WIS-A & 24.03 & 16.85 & 2.73 & 0.750 & 1199.35 \\
\hline & WIS-B & 24.58 & 16.71 & 2.76 & 0.810 & 2853.32 \\
\hline & WIS-C & 26.05 & 16.45 & 2.78 & 0.830 & 1328.33 \\
\hline \multirow{3}{*}{ WES } & WES-A & 26.14 & 16.29 & 2.73 & 0.827 & 1778.65 \\
\hline & WES-B & 26.52 & 16.05 & 2.78 & 0.882 & 1903.16 \\
\hline & WES-C & 27.75 & 15.65 & 2.83 & 0.937 & 2021.82 \\
\hline
\end{tabular}

Table 4. X-ray diffraction results

\begin{tabular}{|c|c|c|c|c|c|c|c|}
\hline \multirow{2}{*}{\multicolumn{2}{|c|}{ Soil designation }} & \multirow{3}{*}{$\begin{array}{c}\text { Smectite } \\
(\%)\end{array}$} & \multirow{3}{*}{$\begin{array}{c}\text { Silica (\%) } \\
12.47\end{array}$} & \multicolumn{2}{|c|}{ Group of feldspar minerals } & \multirow{3}{*}{$\begin{array}{c}\begin{array}{c}\text { Illite } \\
(\%)\end{array} \\
1.89\end{array}$} & \multirow{3}{*}{$\begin{array}{c}\text { Calcite }(\%) \\
2.01\end{array}$} \\
\hline & & & & \multirow{2}{*}{$\begin{array}{c}\begin{array}{c}\text { K-feldspar } \\
(\%)\end{array} \\
23.51\end{array}$} & \multirow{2}{*}{$\begin{array}{c}\begin{array}{c}\text { Plagioclase } \\
(\%)\end{array} \\
3.29\end{array}$} & & \\
\hline \multirow{3}{*}{ BFS } & BFS-A & & & & & & \\
\hline & BFS-B & 58 & 14 & 24.88 & 3.12 & trace & trace \\
\hline & BFS-C & 61.15 & 11.93 & 19.01 & 2.63 & 3.3 & 1.98 \\
\hline \multirow{3}{*}{ WIS } & WIS-A & 58.22 & 25.08 & 10.42 & 2.45 & 2.02 & 1.81 \\
\hline & WIS-B & 59.41 & 27.7 & 9.99 & 2.9 & trace & trace \\
\hline & WIS-C & 63.37 & 20.34 & 10.71 & 1.8 & 2.43 & 1.35 \\
\hline \multirow{3}{*}{ WES } & WES-A & 67.05 & 19.98 & 10.66 & 2.31 & trace & trace \\
\hline & WES-B & 71.74 & 13.4 & 9.91 & 1.85 & 1.89 & 1.22 \\
\hline & WES-C & 76.21 & 11.69 & 8.57 & 1.25 & 1.14 & 1.18 \\
\hline
\end{tabular}


Table 5. Swelling potential assessment results

\begin{tabular}{|c|c|c|c|c|c|c|c|}
\hline \multicolumn{2}{|c|}{ Soil Designation } & $\begin{array}{c}\text { LL } \\
(\%)\end{array}$ & $\begin{array}{c}\text { Swelling potential } \\
\text { based on LL [31] }\end{array}$ & FSR & Swelling potential [23] & $\begin{array}{c}\text { FSI } \\
(\%)\end{array}$ & $\begin{array}{c}\text { Swelling potential } \\
\text { based on FSI } \\
\text { (IS 2720-40) [22] }\end{array}$ \\
\hline \multirow{3}{*}{ BFS } & BFS-A & 58.98 & High & 1.64 & Moderate & 64.31 & Moderate \\
\cline { 2 - 8 } & BFS-B & 61.27 & High & 1.70 & Moderate & 66.66 & Moderate \\
\cline { 2 - 8 } & BFS-C & 64.60 & High & 1.79 & Moderate & 70.19 & Moderate \\
\hline \multirow{3}{*}{ WIS } & WIS-A & 63.78 & High & 1.73 & Moderate & 81.37 & Moderate \\
\cline { 2 - 8 } & WIS-B & 66.22 & High & 1.80 & Moderate & 84.66 & Moderate \\
\cline { 2 - 8 } & WIS-C & 70.64 & Very high & 1.92 & Moderate & 90.30 & Moderate \\
\hline \multirow{3}{*}{ WES } & WES-A & 69.45 & High & 2.20 & High swelling & 116.60 & High swelling \\
\cline { 2 - 8 } & WES-B & 74.31 & Very high & 2.35 & High swelling & 124.60 & High swelling \\
\cline { 2 - 8 } & WES-C & 78.94 & Very high & 2.50 & High swelling & 132.60 & High swelling \\
\hline
\end{tabular}

Table 6. Air Entry Values (AEV)

\begin{tabular}{|c|c|c|c|}
\hline \multirow{2}{*}{} & \multicolumn{2}{c|}{ AEV } \\
\cline { 2 - 4 } & \multicolumn{2}{|c|}{$\begin{array}{c}\text { Matric Suction } \\
\psi_{\mathrm{m}(\mathrm{AEV})}, \mathrm{KPa}\end{array}$} & $\begin{array}{c}\text { Volumetric water content } \\
\theta_{\text {AEV }}\end{array}$ \\
\hline \multirow{3}{*}{ BFS } & BFS-A & 10 & 0.443 \\
\cline { 2 - 4 } & BFS-B & 11.00 & 0.458 \\
\cline { 2 - 4 } & BFS-C & 12.38 & 0.482 \\
\hline \multirow{3}{*}{ WIS } & WIS-A & 14.82 & 0.443 \\
\cline { 2 - 4 } & WIS-B & 15.00 & 0.462 \\
\cline { 2 - 4 } & WIS-C & 17 & 0.490 \\
\hline \multirow{3}{*}{ WES } & WES-A & 16.13 & 0.526 \\
\cline { 2 - 4 } & WES-B & 19.20 & 0.557 \\
\cline { 2 - 4 } & WES-C & 20.20 & 0.588 \\
\hline
\end{tabular}

\subsection{Swelling Properties}

The examination of the expansion potential is conducted according to the swelling soil classification based on the free swell index (FSI) following [22], free swell ratio (FSR) as proposed by [23], and liquid limit (LL) as proposed by [31]. The results of the examination of the swelling characteristics are outlined in Table 5. The results revealed that all samples display swelling features at different levels. Furthermore, a few similitudes and discrepancies in classification are observed. According to $[23,22]$ classifications, WKS exhibits a high expansion potential, whereas BLS and WBS display a moderate expansion potential. Also, it can be observed that the [31] classification approach overestimates the expansion potential. References $[23,32,22]$ classification methods are very similar and precise. These discrepancies can be explained by the differences in classification procedures. Reference [31] classification is related to the LL and did not assess proficiently the expansion potential since the LL represents the boundary between the liquid state and plastic state. FSI and FSR classifications give a better assessment of expansion potential compare with the LL classification.

\subsection{Soil-water Characteristic Curves}

The modeling procedure of the SWCCs using various models found in the literature is described in paragraph 2.3. The SWCCs of BFS-A, BFS-B, and BFS-C are presented respectively in Figures $1,2 \& 3$. The SWCCs of WIS-A, WIS-B, and WIS-C are shown respectively in Figures 4, 5 , $\& 6$. The SWCCs of WES-A, WES-B, and WES-C are presented respectively in Figures 7, 8, \& 9. Model (BL) developed by [30] and model (DB) developed by [28] gives the best fitting suction measurement values than the model (FX) by [1], model (VG) by [27], and model (LN) by [29] This can be explained by the fact that the soils used in this research work exhibit a bimodal pore structure. For a bimodal soil specimen with a bimodal pore structure, the bimodal log-normal distribution model (BL) displays a similar fitting performance to that of (BD) model. However, models (FX, VG, LN) exhibit the best-fit performance for unimodal pore structure.

The SWCCs shown in Figures 2 to 10 are used to determine the matric suction values at AEV and the volumetric water content at $\mathrm{AEV}$. The results are summarized in Table 6 . The matric suction values at AEV are ranging from $10 \mathrm{kPa}$ to $20.20 \mathrm{kPa}$, and the volumetric water contents at $\mathrm{AEV}$ are within the range of 0.443 to 0.588 . WES yield the higher values of matric suction at AEV, WIS exhibits the mean values of matric suction at $\mathrm{AEV}$, and BFS displays the smaller values of matric suction at AEV. This can be explained by the fact that WES 
yields the higher values of clay content ranging from $40 \%$ to $55 \%$, WIS exhibits the mean values of clay content ranging from $34.03 \%$ to $39.73 \%$, and $\mathrm{BFS}$ the smaller amount of clay content within the range of $30.40 \%$ to $35.07 \%$. Reference [32] pointed out that fine-grained such as silt and clay exhibits smaller pore and greater relative surface area and presents a tendency to desaturate at a slower rate. Also, soil compacted with an initial amount of water gives a sample that has differences in GSD and soil structure [33,32]. Moreover, an increase in compaction effort implies an increase in dry unit weight and a decrease in void ratio. Therefore, some differences in the SWCC of the same compacted soil with different efforts are expected. The fine fraction, the compaction effort, and the initial amount of water influence the SWCCs. Reference [32] pointed out that soils with smaller particles such as silt and clay are formed with smaller pore and greater relative surface area and present a tendency to desaturate at a slower rate. Also, soil compacted with an initial amount of water gives a sample that exhibits differences in GSD and soil structure [33,32]. Moreover, an increase in compaction effort implies an increase in dry unit weight and a decrease in void ratio. Therefore, some differences in the SWCC of the same compacted soil with different efforts are expected. The fine-grained fraction, the compaction effort, and the initial amount of water influence the SWCCs. The fitting parameters values of the models VG [27], DB [28], FX [1], LN [29], and BL [30] used to obtain the best fitting SWCCs for the soils BFS, WIS, and WES are respectively summarized in Appendices A, B \& C.

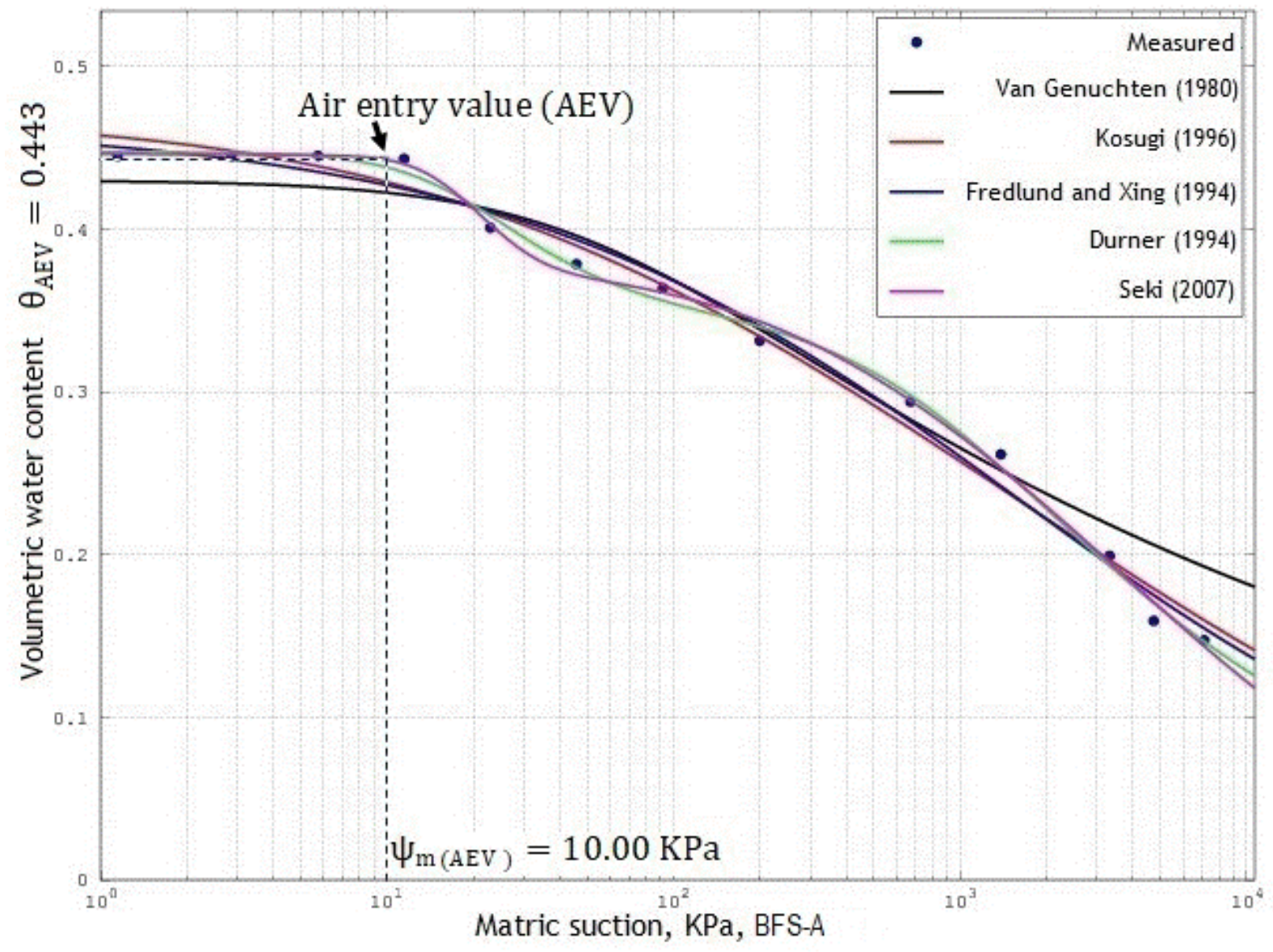

Figure 1. Soil-water characteristic curve for BFS-A as compacted 


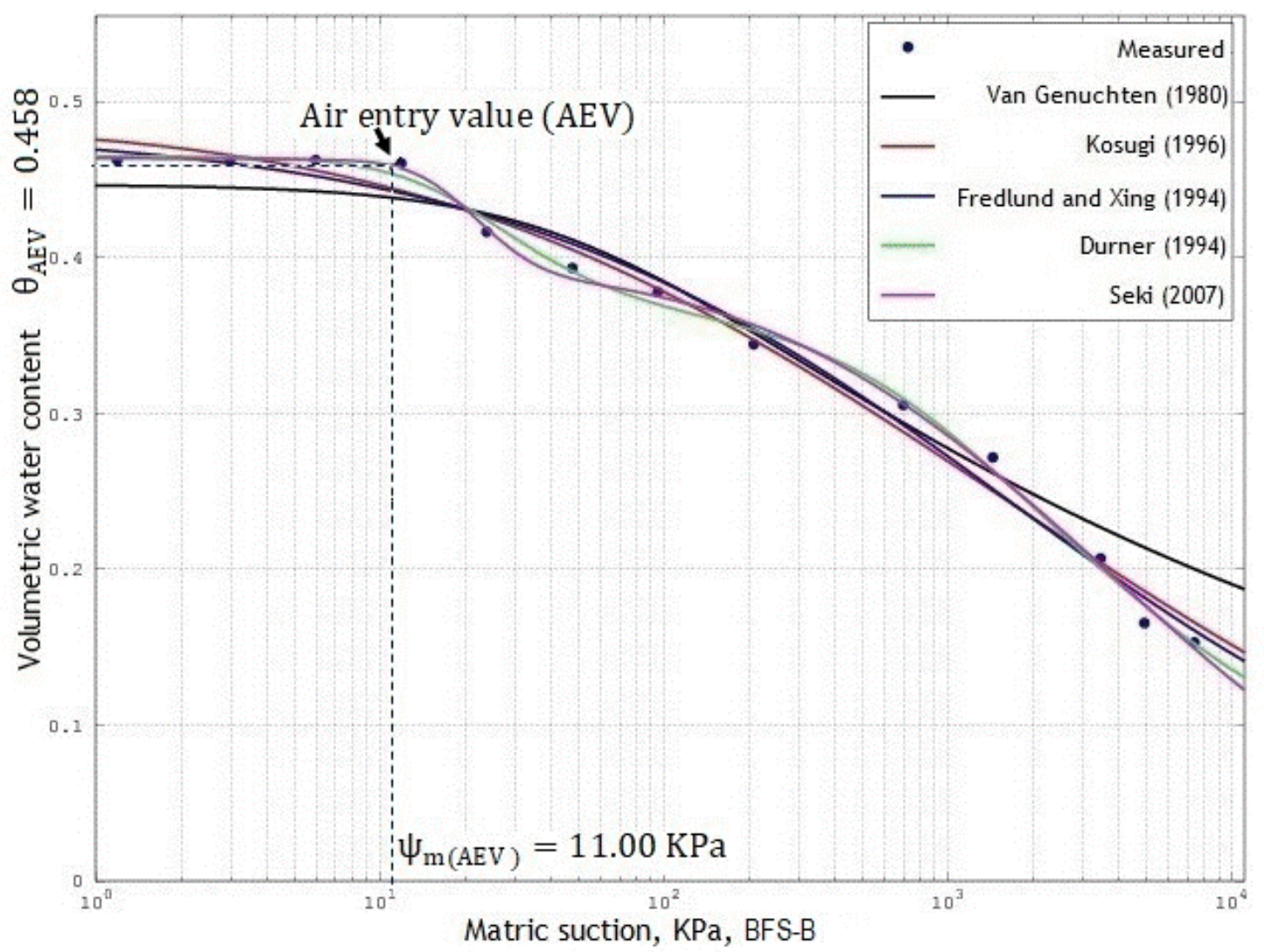

Figure 2. Soil-water characteristic curve for BFS-B as compacted

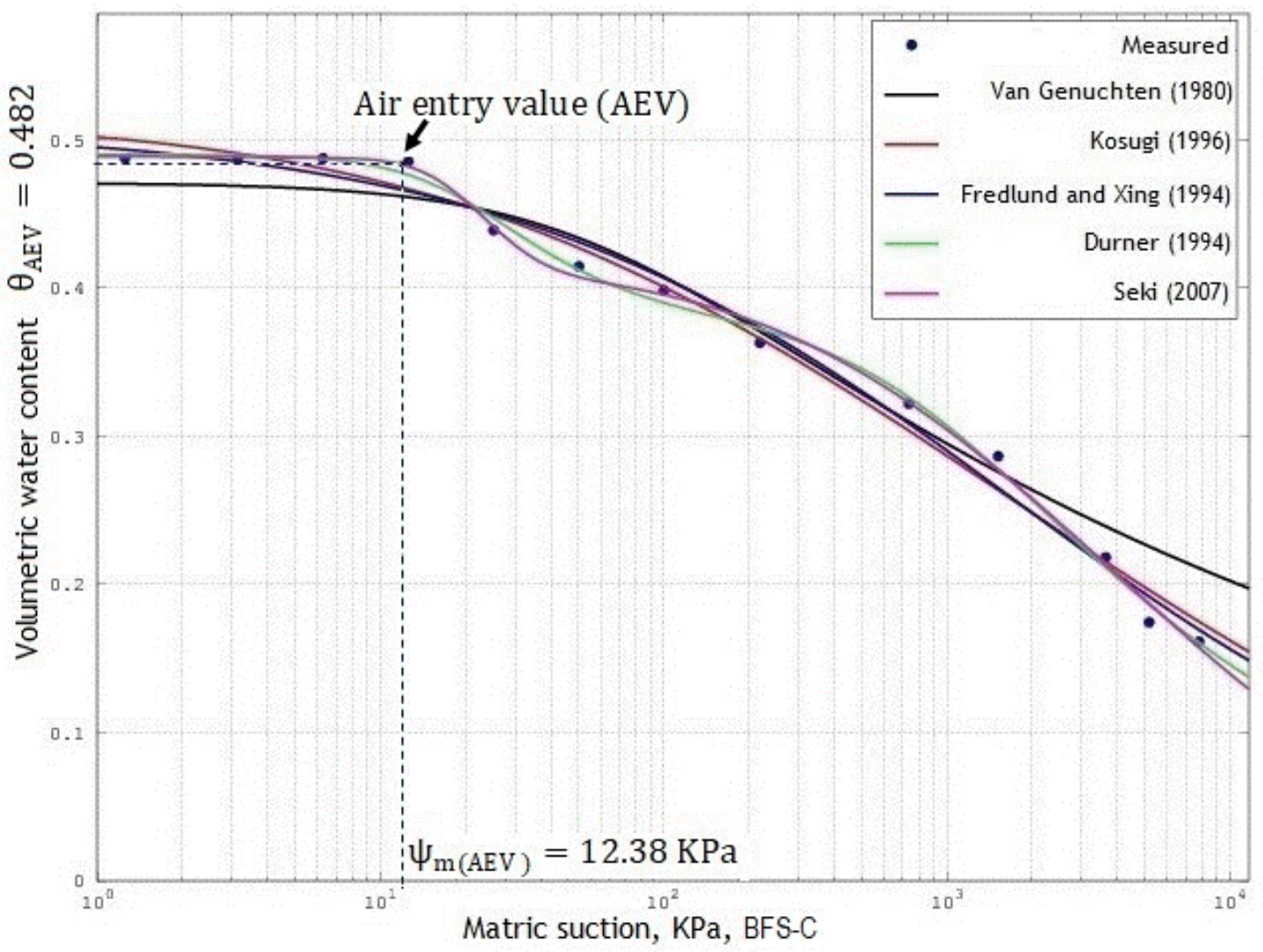

Figure 3. Soil-water characteristic curve for BFS-C as compacted 


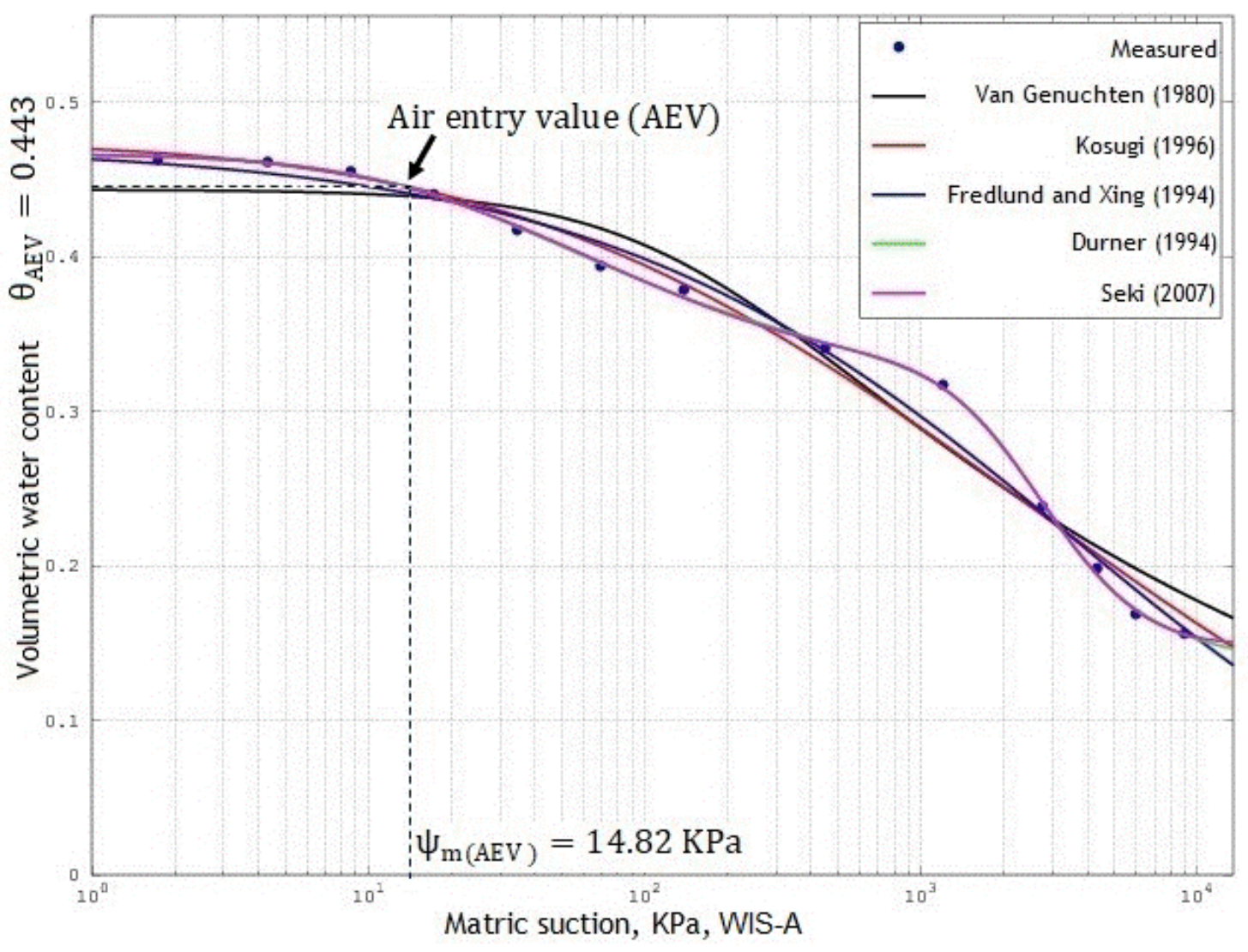

Figure 4. Soil-water characteristic curve for WIS-A as compacted

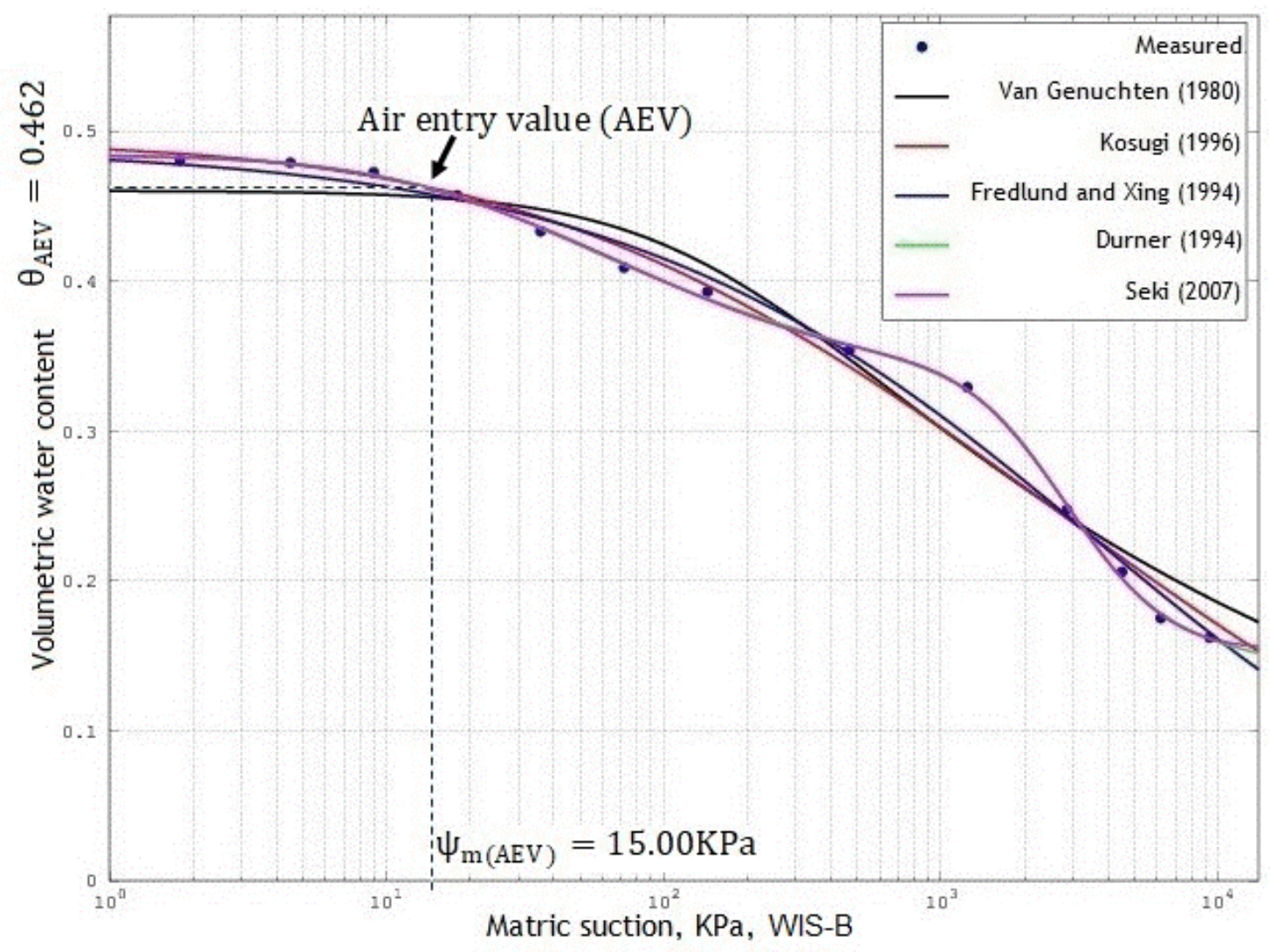

Figure 5. Soil-water characteristic curve for WIS-B as compacted 


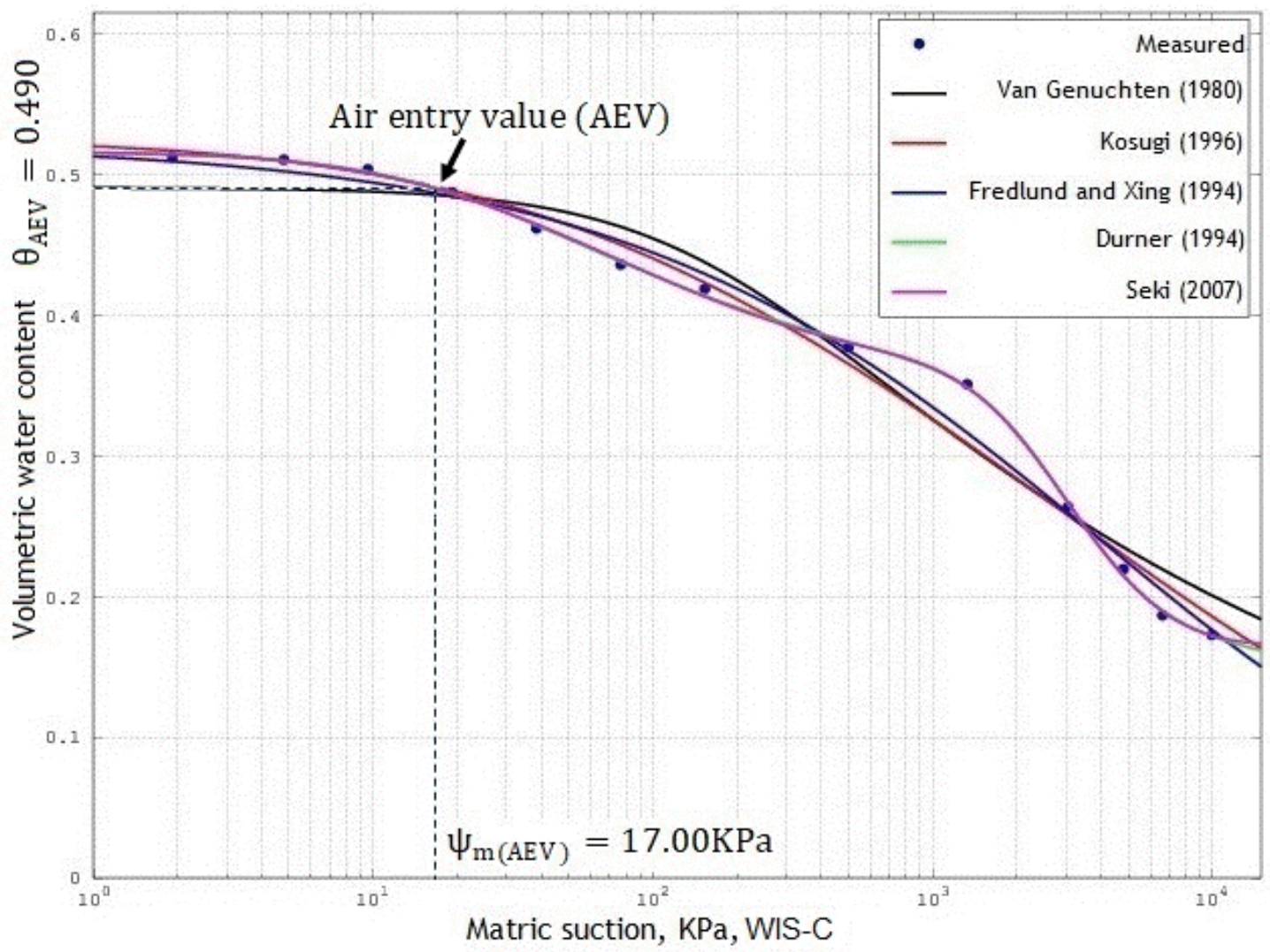

Figure 6. Soil-water characteristic curve for WIS-C as compacted

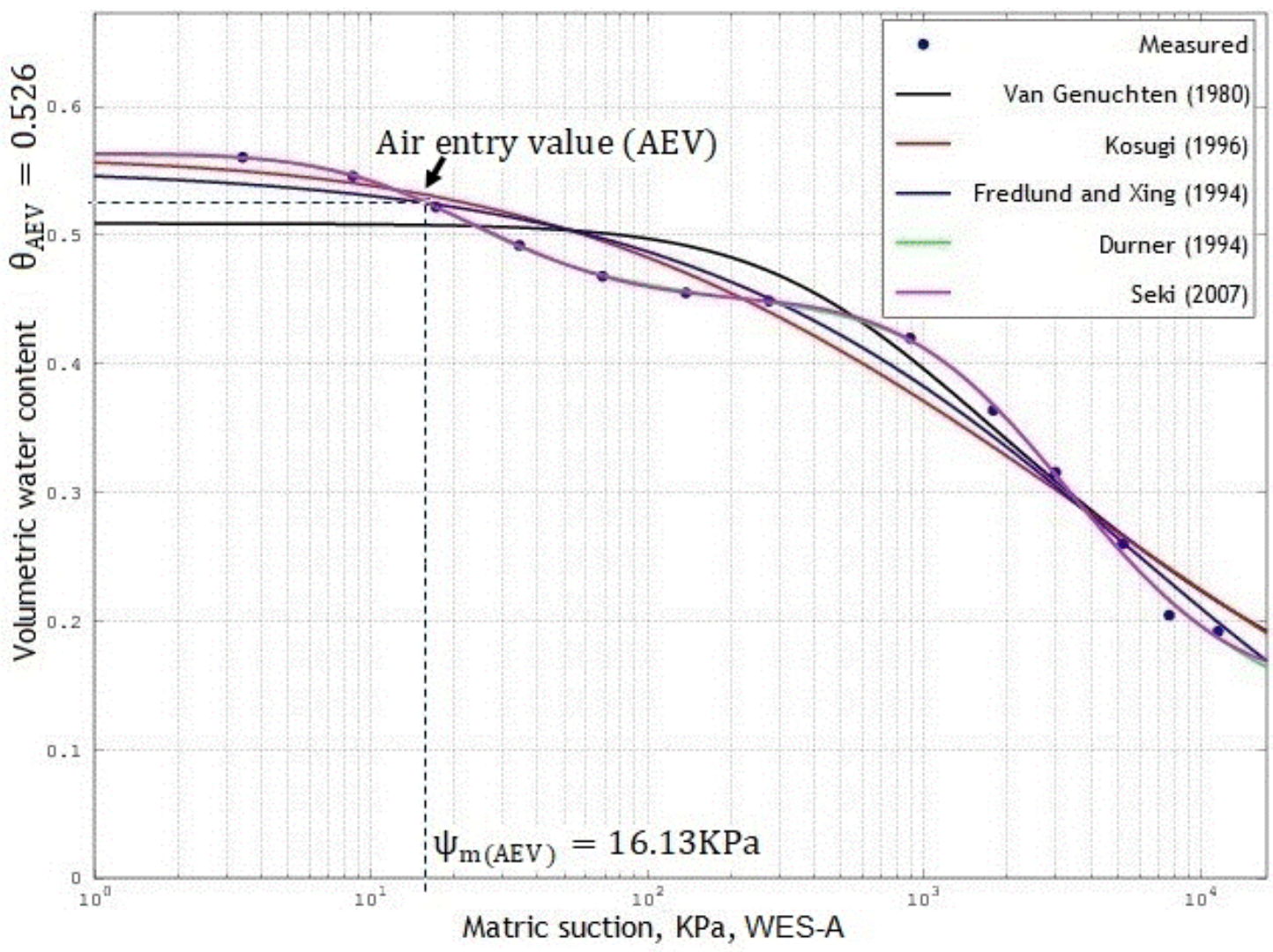

Figure 7. Soil-water characteristic curve for WES-A as compacted 


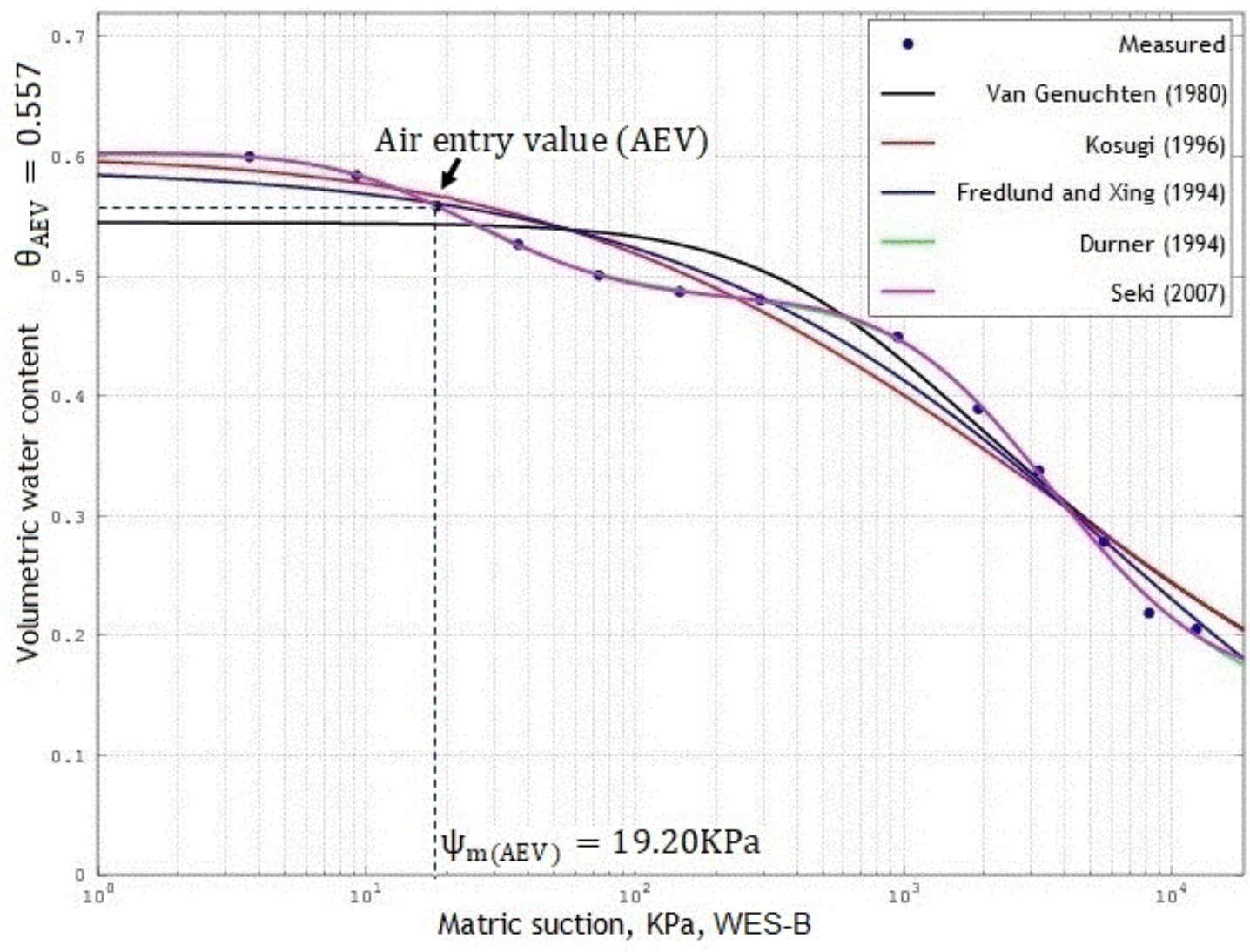

Figure 8. Soil-water characteristic curve for WES-B as compacted

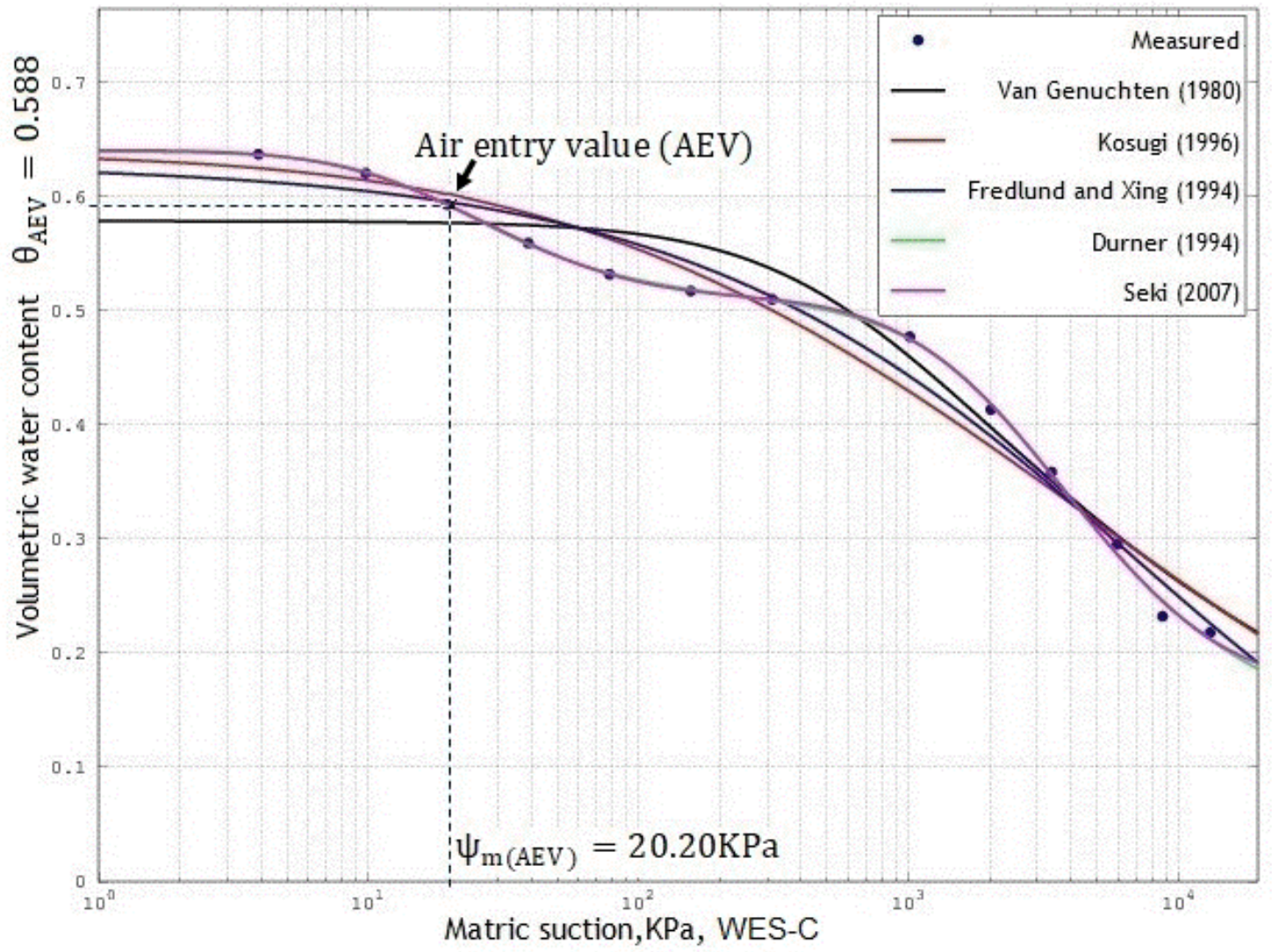

Figure 9. Soil-water characteristic curve for WES-C as compacted 


\subsection{Investigation of the Influences of the Soil Properties on AEV}

3.6.1. Analysis of the Correlation between AEV, Plasticity Index and Linear Shrinkage

The correlation between the AEV, plasticity index and linear shrinkage are presented in Figure 10. It can be noticed that the AEV increments when the plasticity index increments. The results can be clarified by the fact the plasticity index increments with the augmentation of the clay fraction. Additionally, the AEV increases with the increment of voids in the soil. There is a solid linear correlation between the AEV and the plasticity index. The trend line equation is given by $\mathrm{AEV}=-8.20+0.511 * \mathrm{PI}$, with a determination coefficient of $95 \%$. These outcomes concord with the research done by $[3,4,5]$ that reported the important influence of the plasticity index on the AEV in SWCC. Moreover, it can be noticed that the AEV decreases when the linear shrinkage increases. There is a high strength correlation between the AEV and the linear shrinkage. The straight trend line equation is given by $\mathrm{AEV}=+33.03+2.452 * \mathrm{Ls}$, with a determination coefficient of $95.45 \%$. These results are in line with the investigation conducted by [6] that reported the significant impact of the shrinkage on the AEV of heaving soils without specification of the determination coefficient. Colour patterns are used to represent the various range of AEV in Figure 10. The surface plot shows a strong correlation with marginal discrepancies.

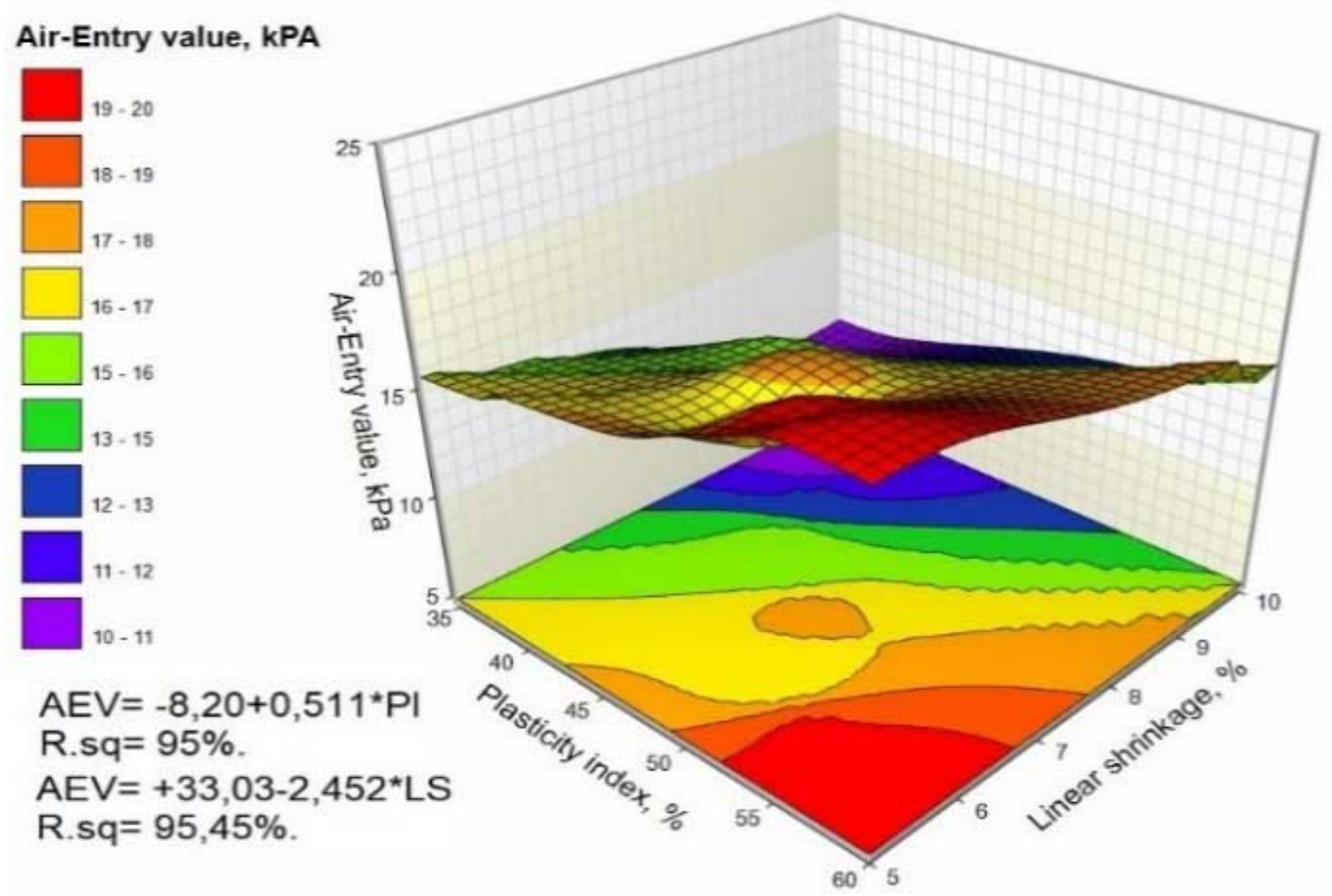

Figure 10. 3D Surface plot AEV vs PI. LS as compacted 


\subsubsection{Assessment of the Relationship between the AEV,} Specific Gravity and Dry Density

The interrelation between the AEV, specific gravity and dry density are presented in Figure 11. It can be observed that the AEV increases when the specific gravity increases. There is a high strength correlation between the AEV and the specific gravity. The mathematical statement of the trend line is given by $\mathrm{AEV}=-143.51+57.93^{*} \mathrm{Gs}$, with a determination coefficient of $90.43 \%$. Besides, it can be observed that the AEV decreases when the dry density increases. There is a high strength interrelation between the $\mathrm{AEV}$ and the dry density. The trend line equation is described by $\mathrm{AEV}=+110.78-5.753 * \mathrm{DD}$, with a determination coefficient of $94.29 \%$. The specific gravity and the dry density exhibit a significant impact on the intensity of the AEV of compacted heaving soils.

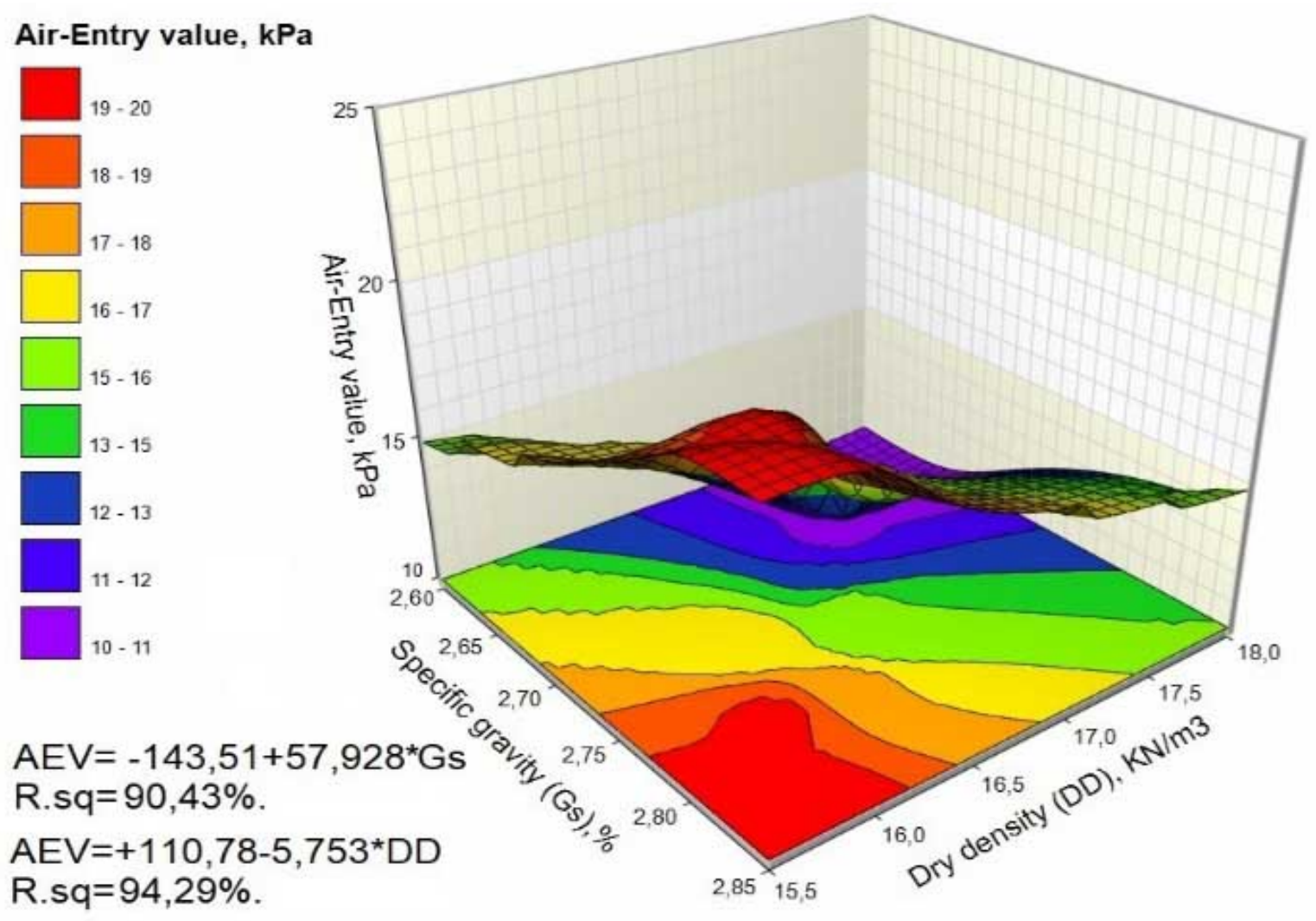

Figure 11. 3D Surface plot AEV vs Gs. Dry density as compacted 


\subsubsection{Analysis of the Correlation between the AEV,} Coefficient of Curvature and Fine Content

The relationship between the AEV, coefficient of curvature, and fine-grained content are presented in Figure 12. It can be observed that the AEV decreases when the coefficient of curvature increments. There is a moderate strength correlation between the AEV and the coefficient of curvature. The trend line equation is described by $\mathrm{AEV}=$ $+21.263-0.0575^{*} \mathrm{Cc}$ with a determination coefficient of $73.16 \%$. Therefore, the influence of the coefficient of curvature on the magnitude of the AEV of compacted heaving soils is not marginal. Further, it can be observed that the AEV increases when the fine-grained (Silts \&
Clays) fraction increases. There is a high strength interrelation between the AEV and the fine-grained (Silts $\&$ Clays) content. The mathematical statement of the trend line is described by AEV $=-16.63+0.451 *$ Fine $(\%)$, with a determination coefficient of $97.95 \%$. These results are contribution to the investigation conducted by $[3,4,11,5]$, which reported the significant impact of the GSD on the SWCC and the behavior of non-saturated soils. However, no study on the influence of fine-grained content, coefficient of curvature, and the AEV is mentioned. Nonetheless, the local extremes observed in the surface plot are induced by the discrepancies in correlations between the AEV and the coefficient of curvature with a determination coefficient smaller than $80 \%$.

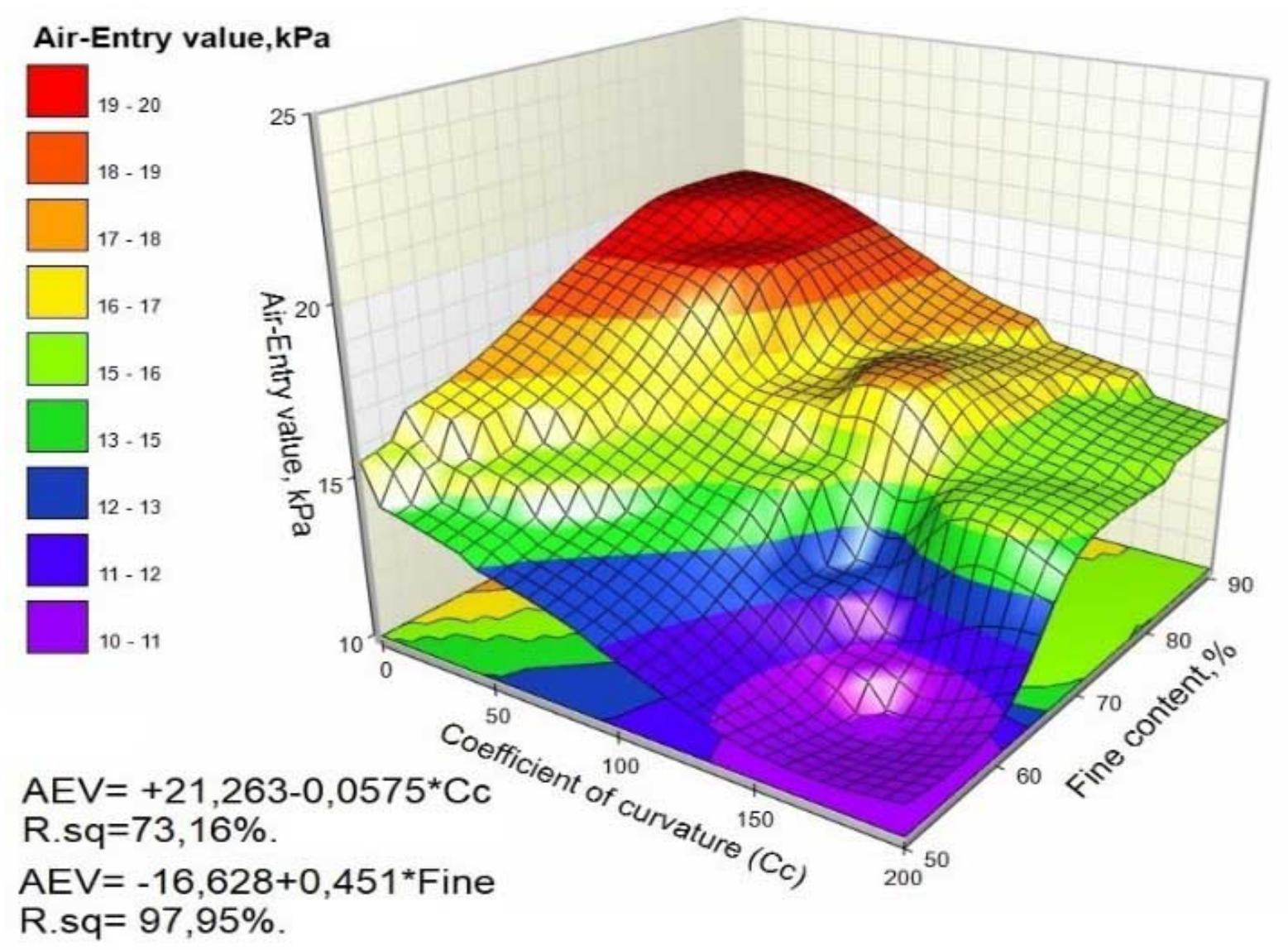

Figure 12. 3D Surface plot AEV vs Cc. Fine content as compacted 
3.6.4. Analysis of the Interralation between the AEV, Void Ratio and Initial Water Content

The correlation between the AEV, void ratio and the initial amount of water are presented in Figure 13. It can be seen that the AEV increments when the void ratio increments. There is a strong relationship between the void ratio and the $\mathrm{AEV}$. The trend equation is given by $\mathrm{AEV}=-$ $20.136+43.37 *$ e, with a determination coefficient of $80 \%$. This can be explained by the fact that the bubbling pressure is the soil moisture deficiency value where the air starts to enter the voids. Besides, the increment of the void ratio leads to soil desaturation and induce the augmentation of the soil moisture deficiency. These results are a contribution to the studies conducted by $[12,14]$, which stated that the void ratio impacts the SWCC but does not give any information about the effect on AEV. Besides, the results are not in line with the research by [13], which reported that the $\mathrm{AEV}$ is inversely proportional to the void ratio. Reference [13] studied do not specify the determination coefficient. These discrepancies can be explained by the fact that in soil compacted at the OWC, the reduction of voids can no longer be enhanced upon an increment of water or energy of compaction. Moreover, it can be observed that the AEV increases when the water content increases. These results can be explained by the fact that at the OWC, the maximum air void is reduced, and the dry unit weight can no longer be enhanced upon the addition of water. There is a strong correlation between the AEV and the water content. The exponential trend line equation is given by $\mathrm{AEV}=+1.323 * \mathrm{e}^{0.0982 * \mathrm{Wi}}$, with a determination coefficient of $94.31 \%$. Therefore, the water content influences the AEV of compacted heaving soils. These results are a contribution to the studies previously conducted by $[12,15,14,9]$, which pointed out that water content exhibits the best impact on SWCC. Besides, the impact of water content on the AEV is not mentioned in these studies.

\section{Air-Entry value, $\mathrm{kPa}$}
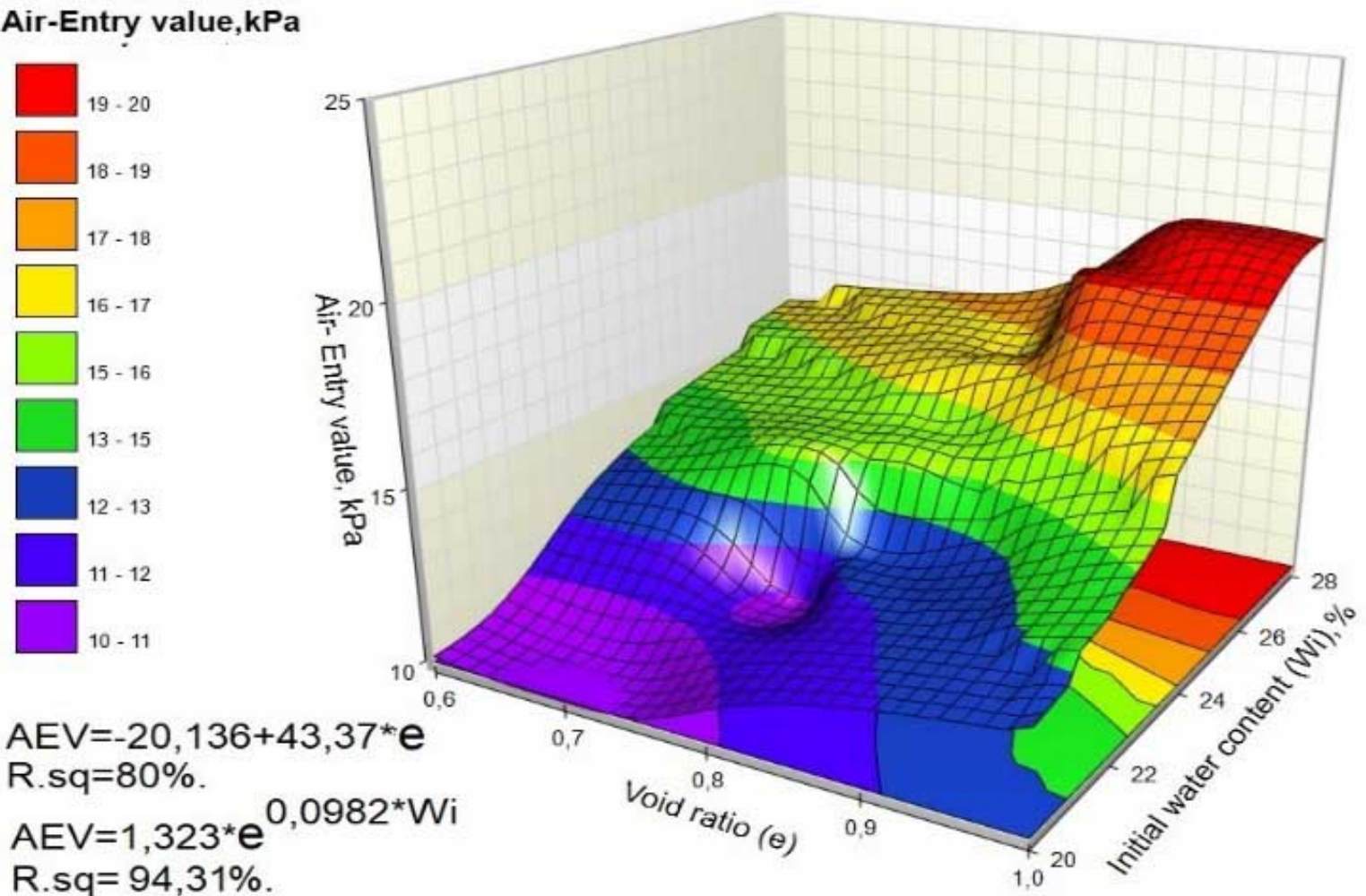

$A E V=-20,136+43,37^{*} e$ R.sq $=80 \%$.

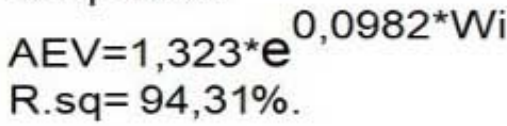

Figure 13. 3D Surface plot AEV vs Void ratio. Wi as compacted 
3.6.5. Analysis of the Correlation between the AEV, Free

Swell Ratio (FSR) and Free Swell Index (FSI)

The interrelation between the AEV, FSR, and FSI are presented in Figure 14. It can be noticed that AEV increases when the FSR increases. There is a moderate correlation between the AEV and the FSR. The mathematical statement of the trend line is given by $\mathrm{AEV}=-4.46+9.96 * \mathrm{FSR}$, with a determination coefficient of $88.68 \%$. Besides, it can be observed that the AEV increases when the FSI increases. There is a strong interrelation between the AEV and the FSI. The trend line equation is described by $\mathrm{AEV}=+3.539+0.125 * \mathrm{FSI}$, with a determination coefficient of $85.72 \%$. The FSR and FSI exhibit a significant influence on the intensity of the AEV of compacted heaving soils. Therefore, the swelling parameters and the AEV of compacted heaving soils are related. The FSI and the FSR can be used to predict the AEV.

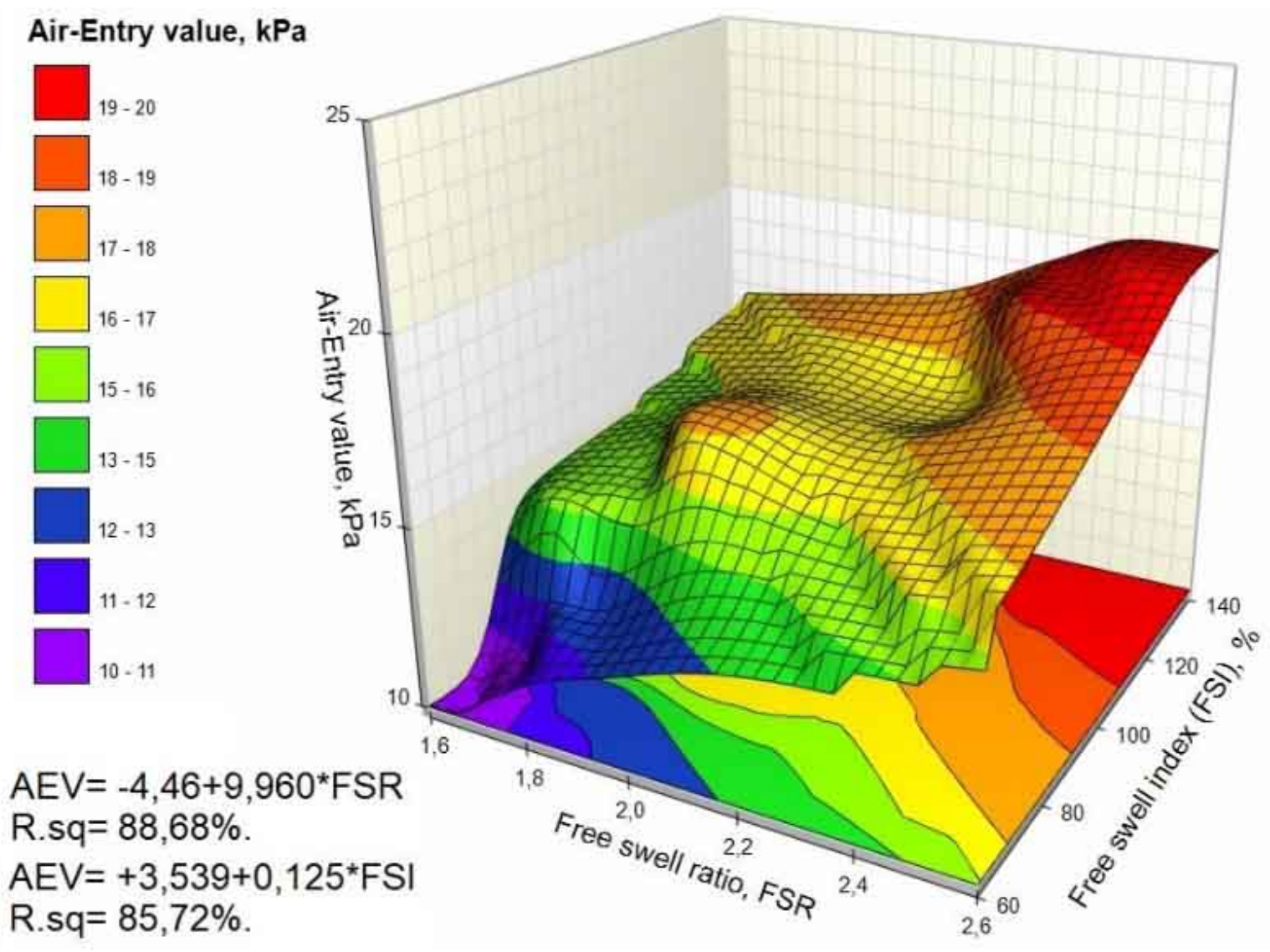

Figure 14. 3D Surface plot AEV vs FSR. FSI as compacted 


\subsubsection{Analysis of the Correlation between the AEV, Smectite Content and Clay Content}

The correlation between the AEV, smectite content and clay content are presented in Figure 15. The AEV increases when the smectite content increases. There is a good relationship between the smectite content and the AEV. The trend line equation is given by $\mathrm{AEV}=-13.823+$ $0.455^{*} \mathrm{PSM}$, with a determination coefficient of $80.61 \%$. These results are in line with the research conducted by [16], which revealed that the smectite content influences the AEV. Also, these results are a contribution to the studies conducted by $[14,11]$, which stated that the smectite mineral content impacts the SWCC. But, the influence of smectite content on the AEV is not mentioned in these studies. Moreover, to observe how the AEV and the clay fraction are related, the type of correlation is presented in a surface plot of AEV versus clay fraction using experimental values. It can be seen that the AEV increases when the clay content increases. These results can be explained by the fact that when the clay content increase, the soil becomes more desaturated, and the soil moisture deficiency increases. There is a good correlation between the AEV and the clay content. The trend line equation is given by $\mathrm{AEV}=-0.5412+0.40 *$ Clay (\%), with a determination coefficient of $84.89 \%$. Thus, the smectite clay mineral and the clay content influence the AEV of heaving soils.

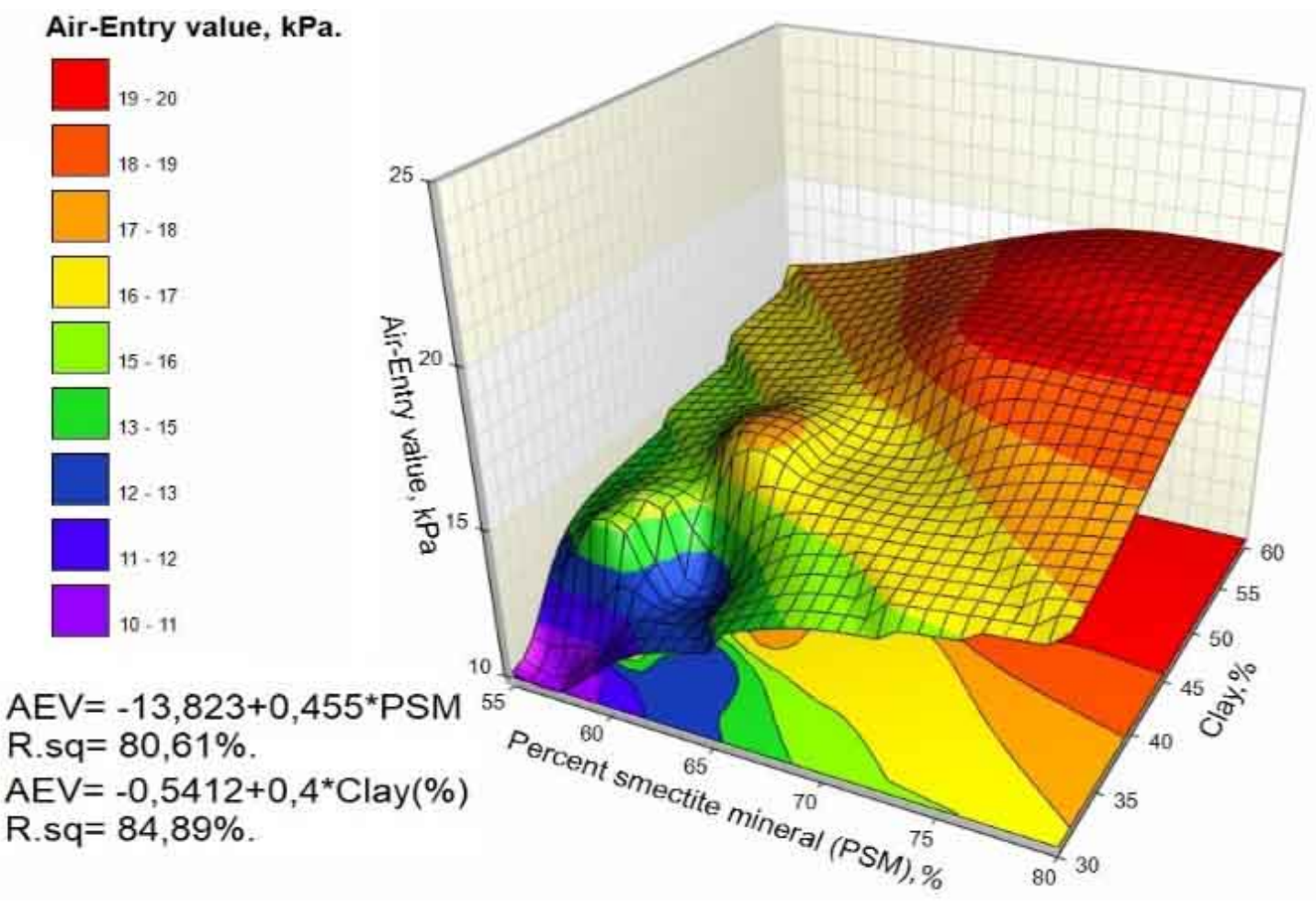

Figure 15. 3D Surface plot AEV vs PSM. Clay as compacted 


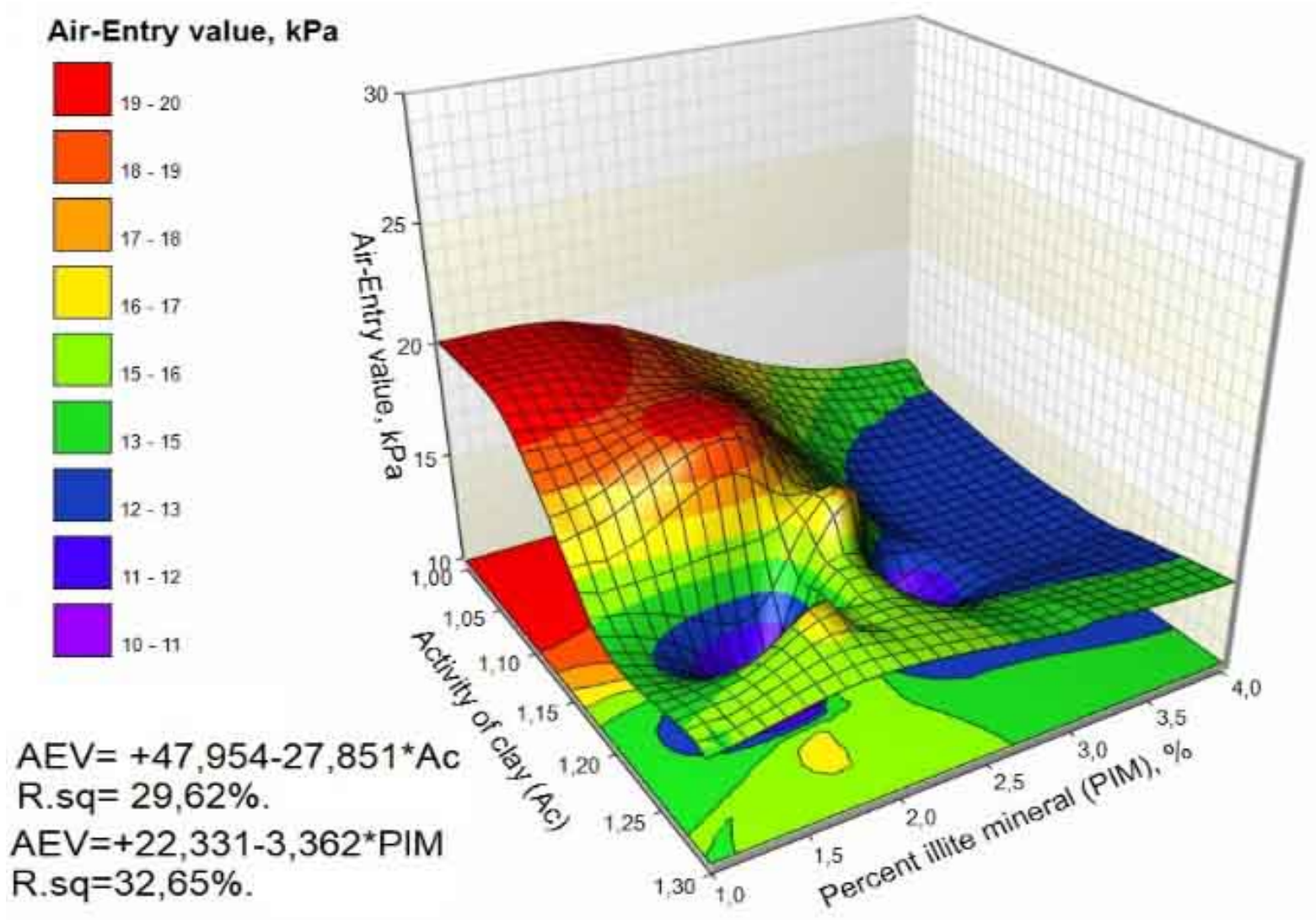

Figure 16. 3D Surface plot AEV vs Ac. PIM as compacted

\subsubsection{Analysis of the Correlation between the AEV,} Activity of Clay and Percent of Illite Mineral

The relationship between the AEV, the activity of clay, and percent of illite mineral are shown in Figure 16. The AEV decreases as the activity of clay increases and exhibits a weak correlation. The mathematical statement of the trend line is described by $\mathrm{AEV}=+47.954-$ $27.851^{*} \mathrm{Ac}$, with a determination coefficient of $29.62 \%$. However, the AEV decreases when the percent of illite mineral increases. There is a weak interrelation between the AEV and the percent of illite mineral. The trend line equation is given by $\mathrm{AEV}=+22.331-3.362 * \mathrm{PIM}$, with a determination coefficient of $32.65 \%$. Moreover, the local extremes observed in the surface plot are induced by the weak strength correlations, with a determination coefficient smaller than $33 \%$ between the AEV, the activity of clay, and percent of illite mineral. Thus, the activity of clay and a non-swelling clay mineral such as illite exhibits a marginal impact on the AEV of compacted heaving soils.

\section{Concluding Remarks and Perspectives}

The AEV is a fundamental factor of the SWCC in unsaturated soil mechanics. In this paper, soil properties are discussed in the context of how they affect the AEV of compacted heaving soils. Among these factors, the percent of smectite mineral exhibits a significant impact on the AEV with a determination coefficient of $80.61 \%$. Swelling properties such as free swell ratio and free swell index influence the AEV with a respective determination coefficient of $85.72 \%, 88.68 \%$. The plasticity index, linear shrinkage, specific gravity, and dry unit weight impact the AEV with a respective determination coefficient of $95 \%$, $95.45 \%, 90.43 \%, 94.29 \%$. The fine-grained content, clay fraction, void ratio, and water content influence the AEV with a respective determination coefficient of $97.95 \%$, $84.89 \%, 80 \%, 94.31 \%$. However, the activity of clay and percent of illite mineral exhibit a marginal effect on the AEV with a respective determination coefficient of $29.32 \%, 32.65 \%$. The AEV is ranging from $10 \mathrm{kPa}$ to $20.20 \mathrm{kPa}$, models DB and BL give the best fitting SWCC. The outcomes of this research work can be used to develop a model to predict the AEV in the SWCC of compacted heaving soils. 


\section{Notations}

\begin{tabular}{|c|c|}
\hline$\Psi:$ & soil suction \\
\hline$\theta:$ & volumetric water content \\
\hline$\theta_{\mathrm{r}}:$ & residual volumetric water content \\
\hline$\theta_{\mathrm{s}}:$ & saturated volumetric water content \\
\hline$\alpha:$ & fitting parameter inversely related to soil suction \\
\hline $\mathrm{n}:$ & Fitting parameter that affect the shape of the curve \\
\hline $\mathrm{w}_{1}$ & weighting factor for the subcurve \\
\hline$\alpha_{\mathrm{i}}:$ & scaling factor that determines the position of the maximum pore sizes, \\
\hline $\mathrm{n}_{\mathrm{i}}, \mathrm{m}_{\mathrm{i}}:$ & dimensionless curve shape parameters \\
\hline e: & Napier's constant \\
\hline $\mathrm{C}_{\mathrm{r}}$ : & an input value related to the residual suction which can be estimated at $1500 \mathrm{kPa}$ for most cases \\
\hline $\mathrm{C}(\Psi)$ : & correction factor \\
\hline $\mathrm{a}:$ & soil parameter related to the air entry of the soil \\
\hline $\mathrm{n}:$ & soil parameter related to the rate of desaturation \\
\hline $\mathrm{m:}$ & soil parameter related to the residual water content conditions \\
\hline$Q(x):$ & $\begin{array}{l}\text { complementary cumulative normal distribution function defined } \\
\text { By } Q(x)=1-\Phi(x) \text { in which } \Phi(x) \text { is a normalized form of the cumulative normal distribution function }\end{array}$ \\
\hline$\sigma:$ & standard deviation of the distribution \\
\hline$\Psi_{\mathrm{m}}:$ & soil fitting parameter \\
\hline$\sigma_{\mathrm{i}}:$ & standard deviation of the distribution \\
\hline$\Psi_{\mathrm{mi}:}$ & soil fitting parameters \\
\hline $\mathrm{R}^{2}$ or R.sq: & coefficient of determination \\
\hline AIC: & Akaike Information Criterion \\
\hline AEV: & Air-entry value \\
\hline ASTM: & American Society for Testing and Material \\
\hline BL: & Seki model of SWCC \\
\hline BFS: & Bloemfontein soil \\
\hline $\mathrm{CH}:$ & high plastic clay \\
\hline Cc: & coefficient of curvature \\
\hline DB: & Durner model of SWCC \\
\hline FSR: & free swell ratio \\
\hline FSI: & free swell index \\
\hline FX: & Fredlund and Xing model of SWCC \\
\hline GSD: & grain size distribution \\
\hline IS: & Indian Standards \\
\hline LN: & Kosugi model of SWCC \\
\hline MDUW & Maximum dry unit weight \\
\hline OWC: & optimum water content \\
\hline PIM: & percent of illite mineral \\
\hline PSM: & percent of smectite mineral \\
\hline SWCC: & soil water characteristic curve \\
\hline SANS: & South African National Standards \\
\hline TMH: & Technical Method for Highways \\
\hline USCS: & unified soil classification system \\
\hline VG: & Van Genuchten model of SWCC \\
\hline WES: & Welkom soil \\
\hline WIB: & Winberg soil \\
\hline
\end{tabular}




\section{Appendices}

\section{Appendix A. SWCCs fitting parameters, BFS}

\begin{tabular}{|c|c|c|c|c|}
\hline $\mathrm{BFS}$ & Model & Parameters & $\mathrm{R}^{2}$ & AIC \\
\hline \multirow{5}{*}{ BFS-A } & Van Genuchten & $\begin{array}{l}\theta_{\mathrm{s}}=0.42989 ; \\
\theta_{\mathrm{r}}=5.647 * 10^{-6} \\
\alpha=0.017725 ; \quad \mathrm{n}=1.1659\end{array}$ & 0.953 & -90.30 \\
\hline & Kosugi & $\begin{array}{l}\theta_{\mathrm{s}}=0.46789 \\
\theta_{\mathrm{r}}=1.8706 * 10^{-7} \\
\psi_{\mathrm{m}}=1584.9 ; \sigma=3.6659\end{array}$ & 0.9867 & -106.43 \\
\hline & Fredlund and Xing & $\begin{array}{l}\theta_{\mathrm{s}}=0.4649 \\
\theta_{\mathrm{r}}=3.8109 * 10^{-7} \\
\mathrm{a}=1455.9 ; \mathrm{m}=2.4366 \\
\mathrm{n}=0.46574\end{array}$ & 0.9877 & -105.46 \\
\hline & Duner & $\begin{array}{l}\theta_{\mathrm{s}}=0.44745 \\
\theta_{\mathrm{r}}=1.6822 * 10^{-5} \\
\mathrm{w}_{1}=0.22098 \\
\alpha_{1}=0.049397 \\
\mathrm{n}_{1}=2.3851 ; \alpha_{2}=0.001225 \\
\mathrm{n}_{2}=1.3945\end{array}$ & 0.99656 & -118.08 \\
\hline & Seki & $\begin{array}{l}\theta_{\mathrm{s}}=0.44608 ; \\
\theta_{\mathrm{r}}=7.2554 * 10^{-6} \\
\mathrm{w}_{1}=0.15043 ; \psi_{\mathrm{m} 1}=21.100 \\
\sigma_{1}=0.40657 ; \psi_{\mathrm{m} 2}=3608.7 \\
\sigma_{2}=2.2019\end{array}$ & 0.99700 & -119.81 \\
\hline \multirow{5}{*}{ BFS-B } & Van Genuchten & $\begin{array}{l}\theta_{\mathrm{s}}=0.44658 ; \\
\theta_{\mathrm{r}}=5.866 * 10^{-6} \\
\alpha=0.017062 ; \quad \mathrm{n}=1.1659\end{array}$ & 0.9539 & -89.313 \\
\hline & Kosugi & $\begin{array}{l}\theta_{\mathrm{s}}=0.48606 ; \\
\theta_{\mathrm{r}}=1.9426 * 10^{-7} \\
\psi_{\mathrm{m}}=1646.5 ; \sigma=3.6659\end{array}$ & 0.9867 & -105.4 \\
\hline & Fredlund and Xing & $\begin{array}{l}\theta_{\mathrm{s}}=0.48295 \\
\theta_{\mathrm{r}}=3.963 * 10^{-7} \\
\mathrm{a}=1512.4 ; \mathrm{m}=2.4366 \\
\mathrm{n}=0.46574\end{array}$ & 0.98769 & -104.47 \\
\hline & Duner & $\begin{array}{l}\theta_{\mathrm{s}}=0.46481 \\
\theta_{\mathrm{r}}=1.7461 * 10^{-5} \\
\mathrm{w}_{1}=0.22098 \\
\alpha_{1}=0.047551 \\
\mathrm{n}_{1}=2.3851 ; \alpha_{2}=0.0011793 \\
\mathrm{n}_{2}=1.3945\end{array}$ & 0.99656 & -117.05 \\
\hline & Seki & $\begin{array}{l}\theta_{\mathrm{s}}=0.46340 ; \\
\theta_{\mathrm{r}}=1.8199 * 10^{-6} \\
\mathrm{w}_{1}=0.15047 ; \psi_{\mathrm{m} 1}=21.917 \\
\sigma_{1}=0.40629 ; \psi_{\mathrm{m} 2}=3746.0 \\
\sigma_{2}=2.2014\end{array}$ & 0.9970 & -118.82 \\
\hline \multirow{5}{*}{ BFS-C } & Van Genuchten & $\begin{array}{l}\theta_{\mathrm{s}}=0.47085 \\
\theta_{\mathrm{r}}=6.185 * 10^{-6} \\
\alpha=0.0161183 ; \quad \mathrm{n}=1.1659\end{array}$ & 0.9539 & -87.937 \\
\hline & Kosugi & $\begin{array}{l}\theta_{\mathrm{s}}=0.51247 ; \\
\theta_{\mathrm{r}}=2.0482 * 10^{-7} \\
\psi_{\mathrm{m}}=1735.9 ; \sigma=3.6659\end{array}$ & 0.9867 & -104.06 \\
\hline & Fredlund and Xing & $\begin{array}{l}\theta_{\mathrm{s}}=0.50920 \\
\theta_{\mathrm{r}}=4.181 * 10^{-7} \\
\mathrm{a}=1594.6 ; \mathrm{m}=2.4366 \\
\mathrm{n}=0.46574\end{array}$ & 0.9876 & -103.10 \\
\hline & Duner & $\begin{array}{l}\theta_{\mathrm{s}}=0.49008 \\
\theta_{\mathrm{r}}=1.8397 * 10^{-5} \\
\mathrm{w}_{1}=0.22098 \\
\alpha_{1}=0.045100 \\
\mathrm{n}_{1}=2.3851 ; \alpha_{2}=0.0011185 \\
\mathrm{n}_{2}=1.3945\end{array}$ & 0.9965 & -115.68 \\
\hline & Seki & $\begin{array}{l}\theta_{\mathrm{s}}=0.48859 \\
\theta_{\mathrm{r}}=1.4799 * 10^{-5} \\
\mathrm{w}_{1}=0.15037 ; \psi_{\mathrm{m} 1}=23.104 \\
\sigma_{1}=0.40582 ; \psi_{\mathrm{m} 2}=3950.9 \\
\sigma_{2}=2.2023\end{array}$ & 0.997 & -117.45 \\
\hline
\end{tabular}




\section{Appendix B. SWCCs Fitting Parameters (WIS)}

\begin{tabular}{|c|c|c|c|c|}
\hline WIS & Model & Parameters & $\mathrm{R}^{2}$ & AIC \\
\hline \multirow{5}{*}{ WIS-A } & Van Genuchten & $\begin{array}{l}\theta_{\mathrm{s}}=0.44316 \\
\theta_{\mathrm{r}}=2.1792 * 10^{-5} \\
\alpha=0.0065788 ; \quad \mathrm{n}=1.2187\end{array}$ & 0.9663 & -93.442 \\
\hline & Kosugi & $\begin{array}{l}\theta_{\mathrm{s}}=0.47419 ; \\
\theta_{\mathrm{r}}=3.7343 * 10^{-6} \\
\mathrm{~h}_{\mathrm{m}}=2543.8 ; \sigma=3.3720\end{array}$ & 0.9839 & -103.05 \\
\hline & Fredlund and Xing & $\begin{array}{l}\theta_{\mathrm{s}}=0.47205 \\
\theta_{\mathrm{r}}=2.8037 * 10^{-7} \\
\mathrm{a}=7185.1 ; \mathrm{m}=3.6862 \\
\mathrm{n}=0.47531\end{array}$ & 0.98850 & -105.42 \\
\hline & Duner & $\begin{array}{l}\theta_{\mathrm{s}}=0.46594 ; \theta_{\mathrm{r}}=0.12655 \\
\mathrm{w}_{1}=0.50804 ; \\
\alpha_{1}=0.049893 \\
\mathrm{n}_{1}=1.3857 \\
\alpha_{2}=4.3103 * 10^{-4} \\
\mathrm{n}_{2}=2.9135\end{array}$ & 0.99946 & -141.11 \\
\hline & Seki & $\begin{array}{l}\theta_{\mathrm{s}}=0.46616 ; \theta_{\mathrm{r}}=0.14876 \\
\mathrm{w}_{1}=0.43478 ; \psi_{\mathrm{m} 1}=67.842 \\
\sigma_{1}=1.5890 ; \psi_{\mathrm{m} 2}=2780.2 \\
\sigma_{2}=0.65859\end{array}$ & 0.99941 & -139.94 \\
\hline \multirow{5}{*}{ WIS-B } & Van Genuchten & $\begin{array}{l}\theta_{\mathrm{s}}=0.46010 \\
\theta_{\mathrm{r}}=2.262 * 10^{-5} \\
\alpha=0.0063367 ; \quad \mathrm{n}=1.2187\end{array}$ & 0.9663 & -92.467 \\
\hline & Kosugi & $\begin{array}{l}\theta_{\mathrm{s}}=0.49231 \\
\theta_{\mathrm{r}}=3.8773 * 10^{-6} \\
\psi_{\mathrm{m}}=2641.0 ; \sigma=3.3720\end{array}$ & 0.9839 & -102.07 \\
\hline & Fredlund and Xing & $\begin{array}{l}\theta_{\mathrm{s}}=0.49008 \\
\theta_{\mathrm{r}}=2.9051 * 10^{-7} \\
\mathrm{a}=7459.7 ; \mathrm{m}=3.6862 \\
\mathrm{n}=0.47531\end{array}$ & 0.9885 & -104.45 \\
\hline & Duner & $\begin{array}{l}\theta_{\mathrm{s}}=0.48375 ; \theta_{\mathrm{r}}=0.13139 \\
\mathrm{w}_{1}=0.50804 ; \\
\alpha_{1}=0.048056 \\
\mathrm{n}_{1}=1.3857 ; \\
\alpha_{2}=4.1517 * 10^{-4} \\
\mathrm{n}_{2}=2.9135\end{array}$ & 0.99946 & -140.14 \\
\hline & Seki & $\begin{array}{l}\theta_{\mathrm{s}}=0.48397 ; \theta_{\mathrm{r}}=0.15445 \\
\mathrm{w}_{1}=0.43478 ; \psi_{\mathrm{m} 1}=70.434 \\
\sigma_{1}=1.5890 ; \psi_{\mathrm{m} 2}=2886.5 \\
\sigma_{2}=0.65859\end{array}$ & 0.99941 & -138.96 \\
\hline \multirow{5}{*}{ WIS-C } & Van Genuchten & $\begin{array}{l}\theta_{\mathrm{s}}=0.49082 \\
\theta_{\mathrm{r}}=2.413 * 10^{-5} \\
\alpha=0.0059401 ; \quad \mathrm{n}=1.2187\end{array}$ & 0.9663 & -90.786 \\
\hline & Kosugi & $\begin{array}{l}\theta_{\mathrm{s}}=0.52517 ; \\
\theta_{\mathrm{r}}=4.1350 * 10^{-6} \\
\psi_{\mathrm{m}}=2817.3 ; \sigma=3.3720\end{array}$ & 0.9839 & -100.39 \\
\hline & Fredlund and Xing & $\begin{array}{l}\theta_{\mathrm{s}}=0.52280 \\
\theta_{\mathrm{r}}=3.1027 * 10^{-7} \\
\mathrm{a}=7957.7 ; \mathrm{m}=3.6862 \\
\mathrm{n}=0.47531\end{array}$ & 0.9885 & -102.77 \\
\hline & Duner & $\begin{array}{l}\theta_{\mathrm{s}}=0.51604 ; \theta_{\mathrm{r}}=0.14016 \\
\mathrm{w}_{1}=0.50804 ; \\
\alpha_{1}=0.045049 \\
\mathrm{n}_{1}=1.3857 \\
\alpha_{2}=3.8919 * 10^{-4} \\
\mathrm{n}_{2}=2.9135\end{array}$ & 0.99894 & -138.46 \\
\hline & Seki & $\begin{array}{l}\theta_{\mathrm{s}}=0.51628 ; \theta_{\mathrm{r}}=0.16476 \\
\mathrm{w}_{1}=0.43478 ; \psi_{\mathrm{m} 1}=75.136 \\
\sigma_{1}=1.5890 ; \psi_{\mathrm{m} 2}=3079.2 \\
\sigma_{2}=0.65859\end{array}$ & 0.99941 & -137.28 \\
\hline
\end{tabular}




\section{Appendix C. SWCCs Fitting Parameters (WES)}

\begin{tabular}{|c|c|c|c|c|}
\hline WES & Model & Parameters & $\mathrm{R}^{2}$ & AIC \\
\hline \multirow{5}{*}{ WES-A } & Van Genuchten & $\begin{array}{l}\theta_{\mathrm{s}}=0.50894 ; \\
\theta_{\mathrm{r}}=1.5927 * 10^{-6} \\
\alpha=0.0018093 ; \quad \mathrm{n}=1.2824\end{array}$ & 0.9483 & -85.438 \\
\hline & Kosugi & $\begin{array}{l}\theta_{\mathrm{s}}=0.56075 \\
\theta_{\mathrm{r}}=1.9665 * 10^{-7} \\
\psi_{\mathrm{m}}=4171.4 ; \sigma=3.4437\end{array}$ & 0.9658 & -90.794 \\
\hline & Fredlund and Xing & $\begin{array}{l}\theta_{\mathrm{s}}=0.55326 \\
\theta_{\mathrm{r}}=2.4283 * 10^{-7} \\
\mathrm{a}=1.3235 * 10^{-4} \\
\mathrm{~m}=3.9520 \\
\mathrm{n}=0.49182\end{array}$ & 0.97575 & -93.263 \\
\hline & Duner & $\begin{array}{l}\theta_{\mathrm{s}}=0.56265 ; \theta_{\mathrm{r}}=0.10309 \\
\mathrm{w}_{1}=0.25377 ; \\
\alpha_{1}=0.067191 \\
\mathrm{n}_{1}=2.0389 ; \\
\alpha_{2}=4.9483 * 10^{-4} \\
\mathrm{n}_{2}=1.8006\end{array}$ & 0.99858 & -126.12 \\
\hline & Seki & $\begin{array}{l}\theta_{\mathrm{s}}=0.56368 ; \theta_{\mathrm{r}}=0.14911 \\
\mathrm{w}_{1}=0.27315 ; \psi_{\mathrm{m} 1}=24.204 \\
\sigma_{1}=1.0285 ; \psi_{\mathrm{m} 2}=3380.7 \\
\sigma_{2}=1.0714\end{array}$ & 0.99876 & -127.89 \\
\hline \multirow{5}{*}{ WES-B } & Van Genuchten & $\begin{array}{l}\theta_{\mathrm{s}}=0.54456 ; \\
\theta_{\mathrm{r}}=1.704 * 10^{-5} \\
\alpha=0.00116909 ; \quad \mathrm{n}=1.2824\end{array}$ & 0.9658 & -89.035 \\
\hline & Kosugi & $\begin{array}{l}\theta_{\mathrm{s}}=0.6000 \\
\theta_{\mathrm{r}}=2.1042 * 10^{-5} \\
\psi_{\mathrm{m}}=4463.4 ; \sigma=3.4437\end{array}$ & 0.9658 & -89.035 \\
\hline & Fredlund and Xing & $\begin{array}{l}\theta_{\mathrm{s}}=0.59198 \\
\theta_{\mathrm{r}}=2.5965 * 10^{-6} \\
\mathrm{a}=1.4162 * 10^{+4} \\
\mathrm{~m}=3.9520 \\
\mathrm{n}=0.49182\end{array}$ & 0.97575 & -91.504 \\
\hline & Duner & $\begin{array}{l}\theta_{\mathrm{s}}=0.60204 ; \theta_{\mathrm{r}}=0.11030 \\
\mathrm{w}_{1}=0.25377 ; \\
\alpha_{1}=0.062795 \\
\mathrm{n}_{1}=2.0389 ; \\
\alpha_{2}=4.624 * 10^{-4} \\
\mathrm{n}_{2}=1.8006\end{array}$ & 0.99858 & -124.36 \\
\hline & Seki & $\begin{array}{l}\theta_{\mathrm{s}}=0.60314 ; \theta_{\mathrm{r}}=0.15954 \\
\mathrm{w}_{1}=0.27315 ; \psi_{\mathrm{m} 1}=25.898 \\
\sigma_{1}=1.0284 ; \psi_{\mathrm{m} 2}=3617.4 \\
\sigma_{2}=1.0714\end{array}$ & 0.9987 & -126.13 \\
\hline \multirow{5}{*}{ WES-C } & Van Genuchten & $\begin{array}{l}\theta_{\mathrm{s}}=0.57852 ; \\
\theta_{\mathrm{r}}=1.810 * 10^{-5} \\
\alpha=0.0015921 ; \quad \mathrm{n}=1.2824\end{array}$ & 0.9483 & -82.106 \\
\hline & Kosugi & $\begin{array}{l}\theta_{\mathrm{s}}=0.63741 \\
\theta_{\mathrm{r}}=2.235 * 10^{-5} \\
\psi_{\mathrm{m}}=4740.4 ; \sigma=3.4437\end{array}$ & 0.9658 & -87.462 \\
\hline & Fredlund and Xing & $\begin{array}{l}\theta_{\mathrm{s}}=0.62889 \\
\theta_{\mathrm{r}}=2.7598 * 10^{-6} \\
\mathrm{a}=1.5041 * 10^{+4} \\
\mathrm{~m}=3.9520 \\
\mathrm{n}=0.49182\end{array}$ & 0.97575 & -89.931 \\
\hline & Duner & $\begin{array}{l}\theta_{\mathrm{s}}=0.63957 ; \theta_{\mathrm{r}}=0.11718 \\
\mathrm{w}_{1}=0.25377 ; \\
\alpha_{1}=0.059125 \\
\mathrm{n}_{1}=2.0389 ; \\
\alpha_{2}=43543 * 10^{-4} \\
\mathrm{n}_{2}=1.8006\end{array}$ & 0.99858 & -122.79 \\
\hline & Seki & $\begin{array}{l}\theta_{\mathrm{s}}=0.64075 ; \theta_{\mathrm{r}}=0.16949 \\
\mathrm{w}_{1}=0.27315 ; \psi_{\mathrm{m} 1}=27.506 \\
\sigma_{1}=1.0285 ; \psi_{\mathrm{m} 2}=3841.9 \\
\sigma_{2}=1.0714\end{array}$ & 0.99876 & -124.55 \\
\hline
\end{tabular}




\section{REFERENCES}

[1] Delwyn G. Fredlund, Anqing Xing, "Equations for the Soil-Water Characteristic Curve," Canadian Geotechnical Journal, Vol. 31, No. 4, pp. 521-532, 1994. DOI: 10.1139/t94-061.

[2] Ning Lu, William J. Likos, "Unsaturated Soil Mechanics," John Wiley \& Sons. Inc, 2004. Hoboken, USA.

[3] Yugantha Y. Perera, Cluadia E. Zapata, William N. Houston, Sandra L. Houston, "Prediction of the Soil-Water Characteristic Curve Based on Grain-Size-Distribution and Index Properties," Geo-Frontiers Congress, Austin, USA, 2005, pp. 1-12, 2005. DOI: 10.1061/40776(155)4.

[4] Pa Suriya, Radha Jayalakshmi, Sudharsan C. Eswar, "Factors Influences the Soil Water Characteristic Curve and its Parameters," International Journal of Engineering Research and General Science, Vol. 3, No. 4, pp. 741-748, 2015. https://www.researchgate.net/publication/320978053 (accessed sept. 6, 2020).

[5] Jinchun Chai, Peerapat Khaimook, "Prediction of Soil-Water Characteristic Curves Using Basic Soil Properties," Transportation Geotechnics, Vol. 22, Article. 100295, 2020. DOI: 10.1016/j.trgeo.2019.100295.

[6] Martin Wijaya, Eng Choon Leong, Harianto Rahardjo, "Effect of Shrinkage on Air-Entry Value of Soils," Soils and Foundations, Vol. 55, No. 1, pp. 166-180, 2015. DOI: 10.1016/j.sandf.2014.12.013.

[7] Linchang Miao, Fei Jing, Sandra L. Houston, "Soil-Water Characteristic Curve of Remolded Expansive Soils," Fourth International Conference on Unsaturated soils, Arizona, USA, pp. 997-1004, 2006. DOI:

$10.1061 / 40802 \% 28189 \% 2980$.

[8] Bo Li, Yulong Chen. "Influence of Dry Density on Soil-Water Retention Curve of Unsaturated Soils and its Mechanism Based on Mercury Intrusion Porosimetry," Transactions of Tianjin University, Vol. 22, No 3, pp. 268-272, 2016.

https://link.springer.com/article/10.1007/s12209-016-2744 -5 (accessed sept. 6, 2020).

[9] Yao Jiang, Wenwu Chen, Gonghui Wang, Guanping Sun, Fanyu Zhang, "Influence of Initial Dry Density and Water Content on the Soil-Water Characteristic Curve and Suction Stress of a Reconstituted Loess Soil," Bulletin of Engineering Geology and the Environment, Vol. 76, No 3, pp. 1085-1095, 2017. DOI: 10.1007/s10064-016-0899-x.

[10] Yulong Chen, "Soil-Water Retention Curves Derived as a Function of Soil Dry Density," GeoHazards, Vol. 1, No. 1, pp. 3-19, 2018. DOI: 10.3390/geohazards1010002.

[11] Young-Suk Song, Seongwon Hong, "Effect of Clay Minerals on the Suction Stress of Unsaturated Soils," Engineering Geology, Vol. 269, Article. 105571, 2020. DOI: $10.1016 /$ j.enggeo.2020.105571.

[12] Jian Zhou, Yu Jian-lin, "Influences Affecting the Soil-water Characteristic Curve," Journal of Zhejiang University-Science A, Vol. 6, No. 8, pp. 797-804, 2005.
https://link.springer.com/article/10.1631/jzus.2005.A0797( accessed sept. 8, 2020).

[13] Alessandro Tarantino, "A Water Retention Model for Deformable Soils," Géotechnique, Vol. 59, No. 9, pp. 751-762, 2009. DOI: 10.1680/. geot.7.00118.

[14] Ali Akbar Heshmati, Mohammad Reza Motahari, "Identification of Key Parameters on Soil Water Characteristic Curve," Life Sci J, Vol. 9, No. 3, pp. 1532-1537, 2012.

[15] Chetia Malaya, Sreedeep Sekharan, "Critical Review on the Parameters Influencing Soil-Water Characteristic Curve," Journal of Irrigation and Drainage Engineering, Vol. 138, No. 1, pp. 55-62, 2012. DOI:

10.1061/(ASCE)IR.1943-4774.0000371.

[16] Aravind Pedarla, Anand J. Puppala, Bhaskar S. Chittoori, Laureano R. Hoyos, Claudia Zapata, Sandra L. Houston, "Influence of Mineral Montmorillonite on Soil Suction Modeling Parameters," Geotechnical Special Publication, pp. 1126-1135, 2012. DOI:10.1061/9780784412121.116.

[17] TMH1-A4, "The Determination of the Linear Shrinkage of Soils," Council for Scientific and Industrial Research, Pretoria, South Africa, 1986. http://asphalt.csir.co.za/tmh/a 4.pdf (accessed sept.3, 2020).

[18] ASTM, "Standard Test Method for Particle-Size Distribution (Gradation) of Soils Using Sieve Analysis," D 6913; 04. 09, American Society for Testing and Materials, PA, USA, 2009. DOI: 10.1520/d6913-04r09.

[19] ASTM, "Standard Test Method for Particle-size Distribution (Gradation) of Fine-Grained Soils Using the Sedimentation (Hydrometer) Analysis," D 7928; 04. 09, American Society for Testing and Materials, PA, USA, 2016. DOI: $10.1520 / \mathrm{d} 7928-16 \mathrm{e} 01$.

[20] ASTM, "Standard Test Method for the Specific Gravity of Soils," D 854; 04. 08, American Society for Testing and Materials, PA, USA, 2014. DOI: 10.1520/d0854-14.

[21] ASTM, "Standard Test Method for Liquid Limit, Plastic Limit, and Plasticity Index of Soils," D 4318; 04. 08, American Society for Testing and Materials, PA, USA, 2005. DOI: $10.1520 / \mathrm{d} 4318-17 \mathrm{e} 01$.

[22] BIS, "Methods of Test for Soils: Part 40 Determination of Free Swell Index of Soils," IS 2720, Bureau of Indian Standards, New Delhi, India, pp. 1-5, 1977. https://law.resource.org/pub/in/bis/S03/is.2720.40.1977.pdf (accessed sept.3, 2020).

[23] Asuri Sridharan, K. Prakash, "Classification Procedures for Expansive Soils," Proceedings of the Institution of Civil Engineers-Geotechnical Engineering, Vol.143, No. 4, pp. 235-240, 2000. DOI: 10.1680/geng.2000.143.4.235.

[24] George William Brindley, George Brown, " X-ray Diffraction Procedures for Clay Mineral Identification Crystal Structures of Clay Minerals and their X-ray Identification," Mineralogical Society, London, Monograph No. 5, pp. 305-359, 1980.

[25] SABS, "Civil Engineering Test Methods, Determination of the Maximum Dry Density and Optimum Moisture Content," SANS 3001, Part GR30, South Africa Bureau of 
Standards, Pretoria, 2016.

[26] ASTM, "Standard Test Method for Measurement of Soil Potential (Suction) Using Filter Paper," D 5298; 04. 08, American Society for Testing and Materials, PA, USA, 2016. DOI: $10.1520 / \mathrm{d} 5298-16$.

[27] Martinus Th. Van Genuchten, "A Closed- form Equation for Predicting the Hydraulic Conductivity of Unsaturated Soils," Soil Science Society of America Journal, Vol. 44, No. 5, pp. 892-898, 1980. DOI:

$10.2136 /$ sssaj $1980.03615995004400050002 x$.

[28] Wolfgang Durner, "Hydraulic Conductivity Estimation for Soils with Heterogeneous Pore Structure," Water Resources Research, Vol. 30, No. 2, pp. 211-223, 1994. DOI: 10.1029/93WR02676.

[29] Ken'ichirou Kosugi, "Lognormal Distribution Model for Unsaturated Soil Hydraulic Properties," Water Resources Research, Vol. 32, No. 9, pp. 2697-2703, 1996. DOI: 10.1029/96WR01776.
[30] Katsutoshi Seki, "SWRC Fit a Nonlinear Fitting Program with a Water Retention Curve for Soils Having Unimodal and Bimodal Pore Structure," Hydrol. Earth Syst. Sci. Discuss, Vol. 4, No. 1, pp. 407-437, 2007. DOI: 10.5194/hessd-4-407-2007.

[31] Wesley G. Holtz, "Engineering Properties of Expansive Clays," Transactions of the American Society of Civil Engineers, Vol. 121, pp. 641-677, 1954.

[32] Sai K. Vanapalli, Delwyn G. Fredlund, Dennis Edward Pufahl, "The Influence of Soil Structure and Stress History on the Soil-Water Characteristics of a Compacted Till," Géotechnique, Vol. 49, No. 2, pp. 143-159, 1999. DOI: 10.1680/geot.1999.49.2.143.

[33] Antonio Gens, Eduardo E. Alonso, Antonio Lloret, "Effect of Structure on the Volumetric Behaviour of a Compacted Soil," In Proceedings of the First International Conference on Unsaturated Soils, Paris, France, Vol. 1, pp. 83-88, 1995. https://trid.trb.org/view/468412 (accessed sept. 6, 2020). 